\title{
Does Marketing Widen Borders? Cross-Country Price Dispersion in the European Car Market
}

\author{
Eyal Dvir* \\ Georg Strasser ${ }^{@}$ \\ Boston College \\ Boston College
}

First Draft: March 1, 2013

This Draft: April 4, 2014

\begin{abstract}
We study cross-country price differences in the European car market using detailed pricing and technical data. Pricing-to-market is pervasive: model-specific real exchange rates for mechanically identical cars differ significantly from unity. They vary significantly across countries and across car manufacturers. We identify the determinants of car price differences in Europe and find strong evidence that car manufacturers price discriminate by manipulating the menu of included car features available in each country. Such bundling decisions sustain cross-country price differences of up to $13 \%$. Although prices adjust to shocks within a few month, relative car prices show no sign of absolute convergence during the period $2003-2011$.

Acknowledgments: We thank Jim Anderson, Rüdiger Bachmann, and Mario Crucini for very useful suggestions. We are also grateful to the participants of the 2014 AEA Meetings, 2013 BCBU Green Line Workshop, 2013 LETC conference, 2013 NBER Summer Institute, and seminar participants at Brandeis University, University of Connecticut, Deutsche Bundesbank, and Laval University for their comments. A special "thank you" for their efforts in data collecting and cleaning goes to our excellent research assistants Omeed Alerasool, Stacey Chan, Krastina Dzhambova, Wills Hickman, Jonathan Hoddenbagh, Eric Parolin and Tara Sullivan. We thank Bart Vanham of PriceWaterhouseCoopers for generously providing us with out-of-print editions of the "International Fleet Guide", and Philippe Syz and Patrick McGervey for converting them to computer code.

Keywords: law of one price, market segmentation, European car market, bundling, international price dispersion, price discrimination
\end{abstract}

JEL Codes: F15, F31, L11, L62, D22

\footnotetext{
${ }^{*}$ Tel.: +1 617552 3674, Email: Eyal.Dvir@bc.edu

${ }^{\circledR}$ Corresponding author at Department of Economics, Maloney Hall, Boston College, 140 Commonwealth Avenue, Chestnut Hill, MA 02467-3806, USA, Tel.: +1 617552 1954, Email: Georg.Strasser@bc.edu
} 


\section{Introduction}

Pricing-to-market (PTM), the practice of differentiating the retail or wholesale price of a good across markets, is an established fact (e.g. Alessandria and Kaboski, 2011; Atkeson and Burstein, 2008; Berman, Mayer, and Martin, 2012; Gron and Swenson, 1996; Strasser, 2013). Much less is known about the exact mechanisms through which PTM is achieved in practice. For example, a recent report of the Canada Senate on the persistent price gap with the U.S. with a special attention to car prices noted that after hearing extensive expert testimony and taking into account differences in regulation and taxation the committee "cannot offer an explanation as definitive as it would have liked for the price discrepancies for products between Canada and the United States" (Day, Smith, Neufeld, and Gerstein. 2013, p. vi). Price differentials between countries are often attributed to the structure of the economy, e.g. to differential distribution costs (Burstein, Neves, and Rebelo, 2003; Corsetti and Dedola, 2005) or border costs (Engel and Rogers, 1996). But in advanced economies transaction and travel costs are low, and governments routinely promote competition through trade agreements and regulatory measures, so one would expect the ability of firms to price to market to be limited. The persistence of PTM in these countries remains therefore something of a puzzle.

In this paper we show that some of these price differences stem from a specific form of price differentiation by manufacturers: versioning an otherwise homogeneous good across countries. In particular, country-specific versions of a car are created by manipulating the menu of included car options and features available in each country. This practice makes PTM feasible and may allow manufacturers to recover some consumer rent. We examine the practice of PTM in what is perhaps the most studied example in the literature: the European car market (e.g. Auer, 2013; Gil-Pareja, 2003; Goldberg and Verboven, 2001, 2005; Mertens and Ginsburgh, 1985; Verboven, 1996a b). Countries of the European Union (EU) are natural candidates for any discussion of market integration. They share a highly integrated transportation infrastructure, a common regulatory framework, and deep trade relations. Not least, most of them either use a common currency (the Euro) or currencies which are credibly pegged to it.

A car, the most significant purchase of a tradeable good that most households make, is a highly visible symbol of European market integration and as such the focus of intense scrutiny. For this reason, and despite exempting the passenger car market from the unrestricted competition article of the EU treaty, the European Commission (EC) aims to increase market integration within Europe: car warranties must be respected across the EU; 
cross-border car buyers are exempt from taxes and fees in the country of purchase; car registration documents are valid EU-wide; even cross-border purchases to and from the British Isles are accommodated by requiring manufacturers to deliver upon request right-hand drive steering cars to dealers on the Continent (European Commission, 2002; European Commission DG-COMP, 2002). ${ }^{1}$

Comparing car prices across countries, however, is a non-trivial exercise, for consumers as well as economists. A typical car buyer in Europe is presented with a menu of standard and optional features and auxiliary services which varies by country, making direct apples-toapples comparison difficult. A basic and necessary contribution of this paper is the creation of a data set which allows conducting price comparisons of identical products. For this purpose we collect and merge data on prices, technical characteristics, and tax regimes, so that we are certain that the feature-adjusted pre-tax price of, for example, a particular Ford Focus purchased by a German buyer from a French dealership is directly comparable to the pre-tax price that same consumer would have paid in Germany. We consider our assessment quite reliable because we know many determining features of the Ford Focus in question: the car's engine size, its emission rating, its model year, applicable tax rates, the standard features offered in each country, and the price of any optional features in each country.

Our data set allows us to calculate the extent of PTM in the European car market, and to test whether European car prices have been converging. Based on this, a second contribution of this paper is to show that PTM in Europe is pervasive throughout the sample period (2003-2011), with little evidence of absolute convergence. This is true across countries that use the euro as well as across the entire EU. It is a surprising finding given the earlier literature's assessment of declining price dispersion in previous years, and given also the vigorous efforts by the European Commission to increase competition in the new car market. Figure 1 presents a typical case. It shows the cross-country price dispersion for the Ford Focus, a mid-size model popular across Europe. We measure the pre-tax, feature-adjusted (i.e. mechanically identical), euro-denominated price to maintain an "apples-to-apples" comparison. Two features of the data stand out: first, substantial variation exists in the price of a Ford Focus across Europe at any given period covered in our data. The difference between the $25^{\text {th }}$ percentile and the $75^{\text {th }}$ percentile is never less than $€ 1500$, and sometimes closer to $€ 2000$. These are economically significant price differences for a car whose mean price hovers between $€ 13300$ and $€ 15600$. Second, price dispersion shows no clear trend over time. The difference between the $25^{\text {th }}$ percentile and the $75^{\text {th }}$ percentile first decreases during

\footnotetext{
${ }^{1}$ We discuss recent regulatory developments in the EU car market in detail in Appendix $B$.
} 
2003-2005, then increases until 2010, and decreases slightly thereafter.

[Figure 1 about here.]

We define the real exchange rate, $r_{t}^{i, c}$, between a given country $c$ in the EU and a base country, for example Germany or the Netherlands, as the relative feature-adjusted, pre-tax, euro-denominated price of car model $i$ in time period $t$. Figure 2 presents a histogram of the log real exchange rate over time. Under the law of one price, these distributions would be concentrated tightly around zero. We see instead that real exchange rates are widely spread out, with no sign of (absolute) convergence to zero over time. If anything, real exchange rates diverge slightly from 2003 to 2011 . Again, this holds across countries that use the euro as well as across the entire EU. ${ }^{2}$

[Figure 2 about here.]

What can explain these features of the data? Our main contribution in this paper is identifying the particular mechanisms which allow PTM to take place. We show not only how prominently price differences reflect country differences but also how these price differences are sustained despite integrated markets. With respect to the former we strengthen earlier findings that manufacturers' prices take advantage of existing market segmentation in Europe. Thus prices respond to differences across countries in, for example, income and tax rates. Our novel finding, however, is about the latter: Car manufacturers seem to price discriminate using differential bundling of their products across markets. Air conditioning (AC), for example, is offered either as a standard feature of the car or as an optional feature with its own price. Importantly, the menu of choices for the same model can and does vary across countries. As a result, only $71 \%$ of air-conditioned cars sold in Denmark were sold with $\mathrm{AC}$ as standard, whereas the respective figure for France was $85 \%$. We find that the price of a European car is statistically and economically affected by the menu of choices offered: for example, if AC was included in the car's price as standard, it was priced on average $€ 608$ cheaper than air-conditioned cars where AC was sold as an option. Since we are able to directly compare the prices of exactly identical cars across countries, we can show that this amounts to price discrimination: the model-specific real exchange rate is significantly

\footnotetext{
${ }^{2}$ It is important to distinguish between absolute and conditional convergence of prices across countries. While there is no evidence of absolute convergence in our data, conditional convergence to a country-specific mean is rapid (See section 3.5) and faster in the period 2003-2011 than in earlier estimates (Goldberg and Verboven 2001, 2005). But we see no evidence of convergence towards a single European price for passenger cars in our data, contrary to recent EU reports (e.g. European Commission, 2009, p.6).
} 
affected when AC is included in the car's price as standard in one country, but is sold as an optional feature in another country. The effect is economically significant as well, ranging to $10 \%$ and more of the car price. This is remarkable given that the two cars are mechanically identical, are produced by the same manufacturer, often at the same location, at similar costs. $^{3}$

We present a simple model of price discrimination across and within countries by bundling to explain these findings. In the model, car customers in some countries disagree more than in other countries about the value of a certain car feature, for example an installed AC. In countries where the willingness to pay of some customers for this particular feature is very high, the manufacturer may charge a high price for the feature, so that only the high-value customers will choose to buy the car with AC installed, while the low-value customers will buy the car without AC. This is optimal if the gains from charging the high-value customers more for the option outweigh the loss of revenue incurred by not selling the option to the low-value customers. In these countries, offering AC as standard would leave the high-value customers with a large consumer surplus and would not be profit-maximizing for the manufacturer. In other countries, however, where the heterogeneity of customers with regards to their willingness to pay for $\mathrm{AC}$ is smaller, trying to separate the customers in the way described might reduce profits instead of raising them. The manufacturer will then offer $\mathrm{AC}$ as standard in those countries, but at a lower price since it has to appeal to the entire customer base, rather than to the high-value customers only. But this scheme is limited in neighboring countries by the ability of customers to purchase across borders: the high-value customers in the former type of countries will purchase the car with $\mathrm{AC}$ in the latter type of countries if cross-border transaction costs are not too high. We derive conditions under which the described price discrimination remains optimal for the manufacturer in presence of cross-border purchases. Note that price discrimination in the model is driven by differences across countries in the composition of demand. It is this effect which we are capturing in our regressions.

We proceed as follows. We first provide a brief overview of the current state of knowledge on PTM and price dispersion in the European car market. In Section 3 we describe our price data in detail and examine price dispersion within Europe. In particular, we replicate the fact that real exchange rates within Europe revert quickly to a long-run mean, and that this mean remains far from unity. After introducing our empirical approach we examine the determinants of these persistent price differentials empirically in Section 4 . We show that

\footnotetext{
${ }^{3}$ Our regressions control for country, brand, and time effects, as well as for a number of country-level variables, car assembly plant locations, car technical features, and other demand variables.
} 
bundling helps explain this persistence of international price differences in Section 5 with an illustrative model and empirical evidence. In Section 6 we apply our methodology to real exchange rates. We conclude in Section 7 with some policy implications.

\section{Cross-Country Price Dispersion: Well Studied, But Only Vaguely Understood}

Due to its visibility and the regulatory attention it receives (described in Appendix B), the market for European new passenger cars has been the subject of many studies. The focus of these are price differentials between countries of the EU, in particular whether they have declined since the start of the common market in 1993. We discuss these studies in Section 2.1. We then relate our paper to other studies on PTM and the law of one price (LOP) in Section 2.2

\subsection{Price Dispersion in the European Car Market}

The studies of the late 1980s and early 1990s (Ginsburgh and Vanhamme, 1989; Kirman and Schueller, 1990; Mertens, 1990; Mertens and Ginsburgh, 1985) arrive at mixed conclusions about price convergence in Europe before 1990. Clearly, the price differences in the early 1990s were still very large (Verboven, 1996a), which most likely contributed to the subsequent regulatory attention the car market received. Verboven (1996a) contains a crosssection nested-logit estimation of a pricing and demand equation for five countries (Belgium, France, Germany, Italy, United Kingdom) for the year 1990. Not surprisingly given the large price differences, all countries except Belgium displayed low price elasticities and therefore local market power and potentially cross-country price discrimination. In the same vein Mertens and Ginsburgh (1985) find that price discrimination is much larger than product differentiation in a hedonic price regression, and that car manufacturers "use product lines to discriminate across EU countries" (see also Ginsburgh and Weber, 2002).

In response to this apparent lack of market integration, the European Commission (EC) in 1993 started collecting pre-tax and post-tax prices for about 75 car models at least once a year. Beginning with the report of Degryse and Verboven (2000) to the Competition Directorate-General of the EC in 2000, this data set (henceforth "EC data set") forms the basis for most subsequent analyses of the European car market.

Degryse and Verboven (2000) base their analysis on pre-tax list prices for the years 1993 
2000 taken from the EC data set and converted into a common currency. There is no evidence of diminishing price differentials of models across countries. Also, price variation across countries differs substantially from model to model. Except for luxury cars, where variation is somewhat smaller in percentage (but not in absolute) terms, price variation appears to be model idiosyncratic. As expected, high tax countries have a comparatively low pre-tax price. A special survey allows Degryse and Verboven (2000) to adjust for differences in customer discounts and dealer margins across countries, but these differences are small and have therefore no effect on the results. More than half of the price differential for individual car models remains unexplained by their explanatory variables (taxes, exchange rates, margins, right-hand drive). Whereas this study works with specification-adjusted list prices, it does not explore - as we do - the impact of the car specification on the price differentials. ${ }^{4}$

The papers that follow these seminal studies describe a car market characterized by substantial price dispersion, though declining over time. ${ }^{5}$ Even today, large price differentials remain (Gil-Pareja and Sosvilla-Rivero, 2008; Goldberg and Verboven, 2004, 2005), and PTM is widespread (Gil-Pareja, 2003). Regarding the sources of price dispersion, Goldberg and Verboven (2001) conclude that cost differences across countries account for a higher fraction of price dispersion than brand-specific markups. Lutz (2004) also finds evidence of variable markups, but concludes that barriers to arbitrage between markets play the bigger role. The full European car price data set, however, which motivated the regulatory action, has not been updated since $2003 .{ }^{6}$ For this paper we build an up-to-date and expanded data set with the same structure as the commonly used pre-2003 data. With this data set we are the first to assess the success of EU regulatory policy in the car market since 2003. We can also examine whether there are any differences in price dispersion across EMU countries (i.e. countries which use the euro) relative to all EU countries.

More generally, recent studies of price convergence and product market integration in the EU (e.g. Engel, Rogers, Veronese, and Midelfart, 2004) find no tendency of price convergence after the introduction of the euro in 1999, but considerable convergence in the

\footnotetext{
${ }^{4}$ The contemporaneous paper by Gaulier and Haller (2000) uses the same EC data set for the period 19931999 only to construct aggregate price indices. Doing so, most of the panel information is lost. They document lower pre-tax prices in high tax countries, as do Kirman and Schueller (1990).

${ }^{5}$ Recently, Gil-Pareja and Sosvilla-Rivero (2012) select 45 models and 15 countries from an updated EC data set. Applying various panel unit roots test to the 1993-2008 data gives them only weak evidence of price convergence.

${ }^{6}$ Most later studies of the European car market work with variants of the pre-2003 data. No study has assessed the success of EU regulatory policy in the car market after 2003 using data comparable to the early studies.
} 
1990s, the period during which most intra-EU trade barriers were lifted. ${ }^{7}$ The end of convergence after the mid-1990's applies to almost any product. Fischer (2012), for example, finds hardly any price convergence of washing machines during the period 1995 to 2005 in a study based on scanner data.

\subsection{Deviations from the Law of One Price and Pricing-to-Market}

Substantial price dispersion within and across countries is extremely common. Moreover, measured price dispersion is often quite large, and difficult to rationalize using common explanations, such as the cost of crossing a border or differences in costs of non-traded goods. In fact, tariffs and regulatory import hurdles have fallen to historic lows across the industrialized world as well as in many developing countries, but price dispersion in traded goods does not seem to have become smaller. Also, price dispersion among US cities is even larger for traded goods than for non-traded goods (Engel and Rogers, 2001). Using micro data, Crucini and Shintani (2008) find no meaningful difference in price dispersion between traded and non-traded goods. At the same time, cross-border arbitrage in some markets can be substantial (Asplund, Friberg, and Wilander, 2007), indicating that there is no lack of potential arbitrageurs. Currently there is no satisfactory explanation as to why price differences across countries persist.

These deviations from LOP have been the subject of intense debate in the international finance literature on real exchange rates for some time. This literature has, since the seminal paper by Engel and Rogers (1996), increasingly used micro data to examine cross-country price dispersion. Whereas for commodities LOP holds (Baffes, 1991), already within a global retailer such as IKEA price differences between currency areas cannot be explained with distribution costs or taxes (Haskel and Wolf, 2001; Hassink and Schettkat, 2003). Online stores of two large fashion chains, as well as of Apple and IKEA, however, in more recent years seem to obey to the law of one price within the Euro Area (Cavallo, Neiman, and Rigobon, 2012) - a comparison which necessarily abstracts from store coupons and customer discount cards.

Our paper revisits this debate but examines a very different market. Instead of small and (after sample selection) easy-to-compare household items, we compare large ticket items, namely cars, which are the largest household expenditure item after buying a house. Com-

\footnotetext{
${ }^{7}$ For French exporters, however, Mèjean and Schwellnus (2009) find considerable convergence of export prices across EU export destinations between 1995 and 2004. An explanation for this is that lower trade barriers attracted smaller firms with no means of implementing PTM to enter the export market.
} 
pared to household items, cars are a very heterogeneous good, but with well-documented differences, which we exploit in this paper. Furthermore, we do not rely on online prices, but dealership prices for made-to-order cars. ${ }^{8}$ Finally, the market we study has been explicitly deregulated to allow for cross-border purchases. That is not the case with online purchases for example, where cross-border purchases are often blocked.

Broda and Weinstein (2008) use Universal Product Codes (UPC) to ensure that they are comparing identical products, and find no additional price dispersion across the border. In contrast, Gopinath, Gourinchas, Hsieh, and Li (2011), also using UPC codes, find a considerable price gap between identical products in stores belonging to the same retail chain but located across the US-Canada border. This price gap is almost entirely driven by variation in wholesale costs borne by the retailer and consistent with full segmentation of markets. However, the essence of a UPC bar code is that the product is identical across countries. In this paper we focus instead on differentiation of the standard bundles of product features, which turns out to be an important avenue for manufacturers of implementing PTM and presumably collecting monopoly rents.

\section{Properties of Feature-Adjusted Car Prices}

In this section we first define the feature-adjusted prices and real exchange rates. Then, we examine the evolution of price dispersion and mean reversion of the real exchange rates. Our sources and data cleaning procedure are described in detail in Appendix A.

\subsection{Price Data}

Our car price data come from the European Commission's Directorate General for Competition. The data set was collected and distributed by the EC as a service to European consumers who wish to compare prices across countries. The data is at the country level, covering all countries who were EU members at the time. Until 2006 (inclusive), the EC published semiannual reports, where prices were reported for May and November of that year, respectively. In 2007, the EC switched to annual reporting (for May, 2007 and then for January of 2008 and later years). Publication of the report ended in $2011 .{ }^{9}$ We cover all price reports from

\footnotetext{
${ }^{8}$ Online distribution of new cars has been extremely uncommon during the sample period. Online car brokers started entering the, for example, German market in 2005, but as of 2011 their market share remained negligible (Dudenhöffer and Neuberger. 2011).

${ }^{9}$ The EC's website offers the following reasoning for ending the survey: "Between 1993 and 2011, the Commission has published annually the [...] Car Price Report. This report has been discontinued. When
} 
November 2003 on. Our data set contains the list prices of new cars, with and without tax, as well as information on standard features and the availability and pricing of several optional features, again pre- and post-tax as appropriate. The data also includes information on the warranty offered on the car, whether the price includes an emergency roadside assistance service, and whether the price includes a delivery charge. The most popular models in Europe are covered, made by 29 different manufacturers or brands, and comprising 148 models in an unbalanced panel. ${ }^{10}$

New cars in Europe are normally custom ordered at the dealership, where the buyer can choose from a menu of available features such as engine type, body color, air conditioning (AC), and an anti-lock breaking system (ABS). List prices for the basic car model and for all available options are determined by the manufacturer, and updated periodically. The dealer usually stocks only a small number of new cars for immediate sale. Normally, customers need to wait while a car which exactly fits their specifications is assembled and delivered to the dealership. Discounts and financing packages are typically determined by the manufacturer as well and apply throughout the country. ${ }^{11}$ Price competition among dealers is quite limited as a result. ${ }^{12}$ Given the limited scope for comparison shopping within countries, European competition authorities are keen to encourage cross-border shopping. Our data set was assembled by the EC for exactly that purpose. Several regulations have been

the report was launched, there were major car price differences among Member States, and it was much more difficult for consumers to compare prices across borders. Since then, the situation has improved greatly, in part due to enforcement action by the Commission, and also thanks to the increased availability of price information on the internet. This means there is no longer a need for the Commission to duplicate this information in the Car Price Report." (European Commission, 2013) The findings of this paper cast some doubt on this assessment of price differences in Europe.

${ }^{10}$ The raw data is publicly available for download at http://ec.europa.eu/competition/ sectors/motor_vehicles/prices/report.html. This data is released online only, via tables in portable document format (PDF). To make the data accessible to quantitative analysis, we converted these into Stata format. Careful checks of the data revealed the need for extensive data cleaning. Since our analysis hinges on the availability and pricing of features and installed options, we painstakingly searched for input errors, inconsistent measurement units, and the like. Appendix A.1 describes the process we employed to standardize and thoroughly clean the data in detail.

${ }^{11}$ Dealership discounts in Europe for newly built-to-order cars do exist, but they are small, rarely exceeding 10\%. Degryse and Verboven (2000) find discounts of a similar magnitude based on reports by undercover shoppers and manufacturer responses. They conclude that "the average discounts do not differ substantially across countries" (Degryse and Verboven, 2000 p. 112), and thus have a negligible effect on real exchange rates.

${ }^{12}$ Some dealers offer "near new" cars, usually last year's models or cars ordered but for any reason not claimed. This is a different market altogether: the cars are sold as-is, and are already fully licensed. This market features much more robust price competition, with significant differences from list prices, similarly to dealer practices in the United States. Supply in this market, however, is limited; it is essentially a clearance market. 
enacted to facilitate cross border car shopping, covering taxation, warranty, insurance, and registration. ${ }^{13}$ Notable regulations include the introduction of EU-wide two-year warranty regardless of country of purchase (European Commission, 1999), and of EU-wide car registration documents (European Commission, 2004). A series of rules contained in the Block Exemption Regulation of 2002 (European Commission, 2002) regulate agreements between manufacturers and dealerships with the express purpose of fostering more competition. For example: manufacturers may select which dealers would be allowed to sell their models, but cannot prevent these dealers from selling to any customer, regardless of residence; dealers on the Continent, where driving is on the right-hand side of the road, cannot be prohibited from ordering cars meant for left-hand-side countries such as the U.K and Ireland; manufacturers cannot require that maintenance be performed only at particular dealerships to maintain warranty; and so on. Note, however, that there is no requirement that manufacturers offer consumers the same choices in all European countries. Manufacturers can and, as we show in this paper, often do offer different menus of choices to car buyers in different countries. Thus, for example, a particular model may be offered with AC as standard in one country, while in a neighboring country the consumer may choose the same model with or without AC. This practice, while completely legal, can result in significant price differences between two mechanically identical cars sold in different countries.

\subsection{Auxilliary Data}

We compile several additional datasets to complement our price data by allowing more accurate cross-country comparisons and adding useful controls.

\subsubsection{Car Specification Data from the UK}

We obtain technical data on all car models sold in the United Kingdom (UK) from the website of the UK government's Royal Certification Agency (RCA). This allows us to expand our knowledge of models' technical specifications, and improve our ability to accurately compare car prices across countries. Every car model sold in Britain must undergo testing and certification by this agency, since each car's official emissions and fuel consumption data are determined in this way. ${ }^{14}$ Manufacturers treat Europe as a single market in terms of their

\footnotetext{
${ }^{13}$ The EC maintains a website to educate European consumers about their rights to shop for cars anywhere in the EU: http://europa.eu/youreurope/citizens/vehicles/index_en.htm

${ }^{14}$ The agency's website http://carfueldata.direct.gov.uk provides the year-by-year results of these tests.
} 
choice of models, i.e., a particular model $i$ sold in the UK will be identical to the same model sold in Bulgaria. ${ }^{15}$ We can therefore treat the UK data as applying to all models in our data. We are able to match almost all of the models in our price data with the models in the RCA data set. The only major exception is the Italian brand Lancia, which was not sold in the UK during the sample period, and which we therefore exclude from our analysis. We match the cars based on engine size, fuel type, and/or engine power, depending on which of these features were noted in the price data. We match manual and automatic cars separately, because RCA tests these separately and thus assigns different emissions and fuel consumption values. ${ }^{16}$

\subsubsection{Taxation Data}

Since cross-border car purchases are conducted on a pre-tax basis, it is imperative that we use the correct pre-tax price. While our price data set contains this information, it does contain many errors. We therefore double-check its accuracy using separate taxation data which we collect from the International Fleet Guide, published by PricewaterhouseCoopers (2004, 2006, 2008, 2009, 2010, 2011). This series of industry publications is designed to give European company fleet managers an accurate snapshot of current tax rates imposed by European countries on the registration of new passenger cars. Information on missing countries and additional detail comes from a recent EU report (European Commission DGMOVE, 2012). All cars in Europe are subject to value added tax (VAT), whose rate differs by country and can change over time. European countries also tax new cars at registration based on several other features such as engine size, engine power, and various emissions: carbon dioxide $\left(\mathrm{CO}_{2}\right)$, hydrocarbons $(\mathrm{HC})$, and nitrate oxides $\left(\mathrm{NO}_{x}\right)$, overall particles emitted, or the overall EU emission standard. Less common are taxes based on fuel consumption, weight, or length of the car. As a result there are large, sometimes very large, differences in effective tax rates across countries. While these differences should not directly play a role in the decision to purchase cross-border, they may have a role in manufacturer's pricing decisions

\footnotetext{
${ }^{15}$ This is not true globally: North American and Asian models can be mechanically different from the European version.

${ }^{16} \mathrm{As}$ a rule, we match the models in each EC survey period to the models which were tested at the same time. However, if there are no tests of the relevant model close to the time of the EC survey, we use test results from a future or past date, as long as we are certain that all relevant specifications match. We employ extensive cross-checks using all available sources to rule out any false positives (i.e. erroneously matched but substantially different models, e.g. in engine size or fuel type). Unfortunately engine power is not always noted by the RCA, nor is it always reported in the EC survey. When neither the EC survey nor the RCA data contains engine power, we impute this variable using standard methods.
} 
and therefore may contribute to price discrimination.

Based on these reports we calculate, at each point in time and for each country, the tax due at the time of the first registration for each car model, given the car's price, features, and emissions. This allows us to uncover reporting errors in the EU data set, which turn out to be particularly egregious for the Seat brand. ${ }^{17}$ The total tax ranges from about $€ 600$ for a Peugeot 107 in Luxemburg 2011 to more than $€ 170000$ for a BMW 730D in Denmark in 2010. The small Peugeot 107 is subject to the lowest effective tax rate in the sample. Including VAT, the effective tax rate is less than $7 \%$ of the pre-tax price, because of tax incentives. On the other end of the spectrum, an Audi A8 in Denmark is subject to an effective tax of more than $240 \%$. In 2011, the median effective tax rate across all models as a percentage of the pre-tax price was lowest in Luxemburg (15.0\%) and Germany (19.5\%) and highest in Greece (63\%) and Denmark (189\%).

\subsubsection{Assembly Plant Location}

Price differences across countries may arise simply due to transportation costs. We control for delivery costs when we observe them in our price data set, and complement that by collecting annual data on the European assembly locations of all car models sold in Europe. We obtain this from the industry publication Automotive News Europe. ${ }^{18}$ For each modelcountry pair we calculate the distance from the nearest assembly plant to the country's capital city, using exact coordinates and applying the great circle formula. Some models are not produced in Europe at all, but are imported from the US or Japan. For these models - mostly Japanese and Korean brands - we calculate the distance from the European port of entry if we know what it is. For some models we could not get this information; we assume that these models are imported through Rotterdam, the largest port in Europe.

\subsubsection{Brand Centrality}

Brand-specific demand factors could also account for price differences across countries: Belgians may prefer Toyota, while French customers may prefer Honda. To control for these effects, we collect data from the internet search engine Google on brand proximity. Google

\footnotetext{
${ }^{17}$ Because of obvious misreporting of pre-tax prices of Seat models for almost all countries in the EU data set, we exclude Seat models from most of the subsequent analysis. Including Seat does not alter the results, but adds auto-correlation to the error term.

${ }^{18}$ The data is available at the website europe.autonews.com, which requires a subscription for some years. We have data for 2003-2008, and for 2012. We interpolate the missing years. Assembly locations do not change much over time.
} 
Insights reports which search terms are most commonly entered together with the brand names in our sample. In particular, we observe how often two brands are searched for together. Using this information we are able to calculate the centrality of each brand in a given country, relative to all other brands. We interpret this measure as follows: if a brand is relatively central, it is seen by potential car buyers in that country as relatively substitutable to other brands. Therefore the brand manufacturer's ability to demand a higher price will be more limited. ${ }^{19}$ The centrality measure varies by country and brand. It ranges from zero (about $7 \%$ of all observations) to slightly more than 0.5 for Toyota in Malta. Overall, Toyota is the most central brand, with a centrality average of 0.36 across all countries, followed by Nissan and Citroen. The most idiosyncratic brands are MG Rover and Land Rover, with a centrality average close to zero, followed by Mini and Saab.

\subsubsection{Country-specific controls}

Finally, we collect country-level data on population and GDP per capita (constant international prices) from Eurostat, the statistical office of the EU. ${ }^{20} \mathrm{We}$ also have data on the indirect taxes paid at the pump by consumers when they purchase gasoline or diesel fuel, from the EC's Oil Bulletin. ${ }^{21}$ These taxes are given in euro cents (using nominal exchange rates as needed) per liter of the relevant fuel. We see these variables as useful controls, since they can affect demand for particular types of cars and therefore potentially affect pricing by manufacturers.

\subsection{Definitions}

We take great care to make sure that we are comparing apples to apples, i.e. that we observe prices in different countries of identical cars. The EC data set contains identifying technical information on the car models, such as engine size, fuel type, and engine power. The cars offered also differ across countries in the availability and pricing of options: whether the model is sold with or without AC, an automatic gearbox (AGB), ABS, power steering, or an airbag; and whether the steering is on the right or left. We define a model $i$ as the fullyequipped version of the car in question. Thus, for example, we will record the price, in every country in which it is sold, of a Peugeot 207, 1.4 liter gasoline engine, 5 doors, 90 horse

\footnotetext{
${ }^{19} \mathrm{We}$ describe the data collection and the calculation of the eigenvector centrality measure in more detail in Appendix A.2.

${ }^{20}$ Available at ec . europa .eu/eurostat

${ }^{21}$ Available at ec.europa.eu/energy/observatory/oil/bulletin_en.htm.
} 
power $(66 \mathrm{~kW})$, manual transmission, with $\mathrm{AC}, \mathrm{ABS}$, power steering, and airbags. We define the feature-adjusted, pre-tax car price $P_{t}^{i, c}$, as the pre-tax price in country $c$ in period $t$ of this fully-equipped model $i$. This definition ensures that our cross-country price comparisons are correct. Our definition of "fully-equipped" does not extend to choice of transmission. Instead we treat the manual and automatic versions of the same car as different models. ${ }^{22}$ There are many instances in the data where we observe $P_{t}^{i, c}$ for some countries, but not all; for the other countries we might observe the price of a slightly different model, $P_{t}^{j, c}$, where model $j$ typically differs from model $i$ in one detail such as engine size or power. We treat these as two separate models and do not compare their prices across countries. We exclude from our analysis cars where some of the technical data is missing, inconsistent across countries, or clearly wrong. Our analysis is based on pre-tax prices, because European buyers of new cars pay registration taxes in their country of residence, not in the country in which they buy the car.

We define the model-specific real exchange rate as the logarithmic difference between the feature-adjusted price in each country (converted into euros if necessary) and the price in a base country. We choose the Netherlands as base country because of its intermediate car price level as well as its central location. ${ }^{23}$ Denoting the natural logarithm of the price level by $p_{t}^{i, c}=\log \left(P_{t}^{i, c}\right)$ the model-specific real exchange rate is $r_{t}^{i, c}=p_{t}^{i, c}-p_{t}^{i, N L}$.

In the case of countries where driving is on the left side of the road (UK, Ireland, Cyprus, and Malta), the real exchange rate is defined as the log difference between the car's price with all available options in that country and the price of an exactly identical, right-hand steering car in the Netherlands. To make that comparison, we add the pre-tax price of the right-hand steering option to all car models in the Netherlands when calculating the real exchange rate vis-à-vis any of these countries.

\subsection{Price Dispersion and Violations of the LOP}

We look first at the evolution of price dispersion over time in the entire European car market.

[Figure 3 about here.]

\footnotetext{
${ }^{22} \mathrm{We}$ consider gearbox type a mechanical property and not a feature, because the technical specifications differ by gearbox type, especially regarding emissions. See Section 3.2.1. An automatic Ford Fusion and a manual Ford Fusion are thus treated as separate models.

${ }^{23}$ See Table 12 in Appendix C.1 Our choice is the same as the one of Goldberg and Verboven (2004 p.503). The results with Germany as base country are essentially the same.
} 
Figure 3 shows the range of within-model price dispersion across models, for each survey period. We define model price dispersion, $\Xi_{t}^{i}$, as the standard deviation of the log pre-tax, feature-adjusted price $p_{t}^{i, c}$ for a given model $i$ at a given time $t$ across countries $c$. Until 2008 there is no trend in the level of price dispersion, and its variation across models remains about the same from year to year. In 2009 the average dispersion of car prices jumps up drastically for all models. This observation of a very similar dispersion of models shows that for the most part country-specific, not model-specific price movements are the reason for the deviation in 2009. This may due to the heterogeneous performance of European countries during the recession, as well as large exchange rate movements of some European currencies vis-à-vis the euro. Also, "cash for clunkers" programs in some countries may have stabilized car prices in those countries, whereas countries without such programs experienced much larger price drops. The following two years show a slow convergence toward the pre-2008 situation, but in 2011 the average dispersion is still higher than in 2008. The behavior of the outlier models in 2009 is particularly interesting, since it exposes large differences among manufacturers in response to the crisis: some models' prices converged, while others diverged. After one year most, and by 2011 all but one, of these idiosyncratic prices have disappeared.

A panel regression leads to similar conclusions: regressing the price dispersion on a time trend and model fixed effects $\left(\Xi_{t}^{i}=\alpha_{1}^{i}+\alpha_{2} t+\varepsilon_{t}^{i}\right)$ uncovers a highly significant upward time trend, as shown in the first column of Table 1 . That is remarkable given previous findings in the literature of declining price differences in the European car market. We analyze a later period than most other papers in the literature, thus there is no contradiction. Whatever convergence to absolute price parity has been in this market in the 1990's and early 2000's, it has stopped and perhaps even reversed itself after 2003.

We next investigate whether the increase over time in our price dispersion measure occurred at a similar pace across broad subgroups of car models. We use the EC's classification of models into the following seven segments: mini cars (segment A), small cars (B), medium cars (C), large cars (D), executive cars (E), luxury cars (F), and multi-purpose and sports utility cars $(\mathrm{G})$. Our random effects regression specification has the structure

$$
\Xi_{t}^{i}=\alpha_{1}^{s(i)}+\alpha_{2}^{s(i)} t+\beta_{1} x^{b(i)}+\beta_{2} y_{t}^{i}+v^{i}+\varepsilon_{t}^{i},
$$

where $v^{i \text { iid }} \sim\left(0, \sigma_{v}^{2}\right)$ and $\varepsilon_{t}^{i \text { iid }} \sim\left(0, \sigma_{\varepsilon}^{2}\right) . s(i)$ denotes the segment, and $b(i)$ denotes the brand of model $i$. We include a number of controls: $x^{b(i)}$ are brand-specific variables like brand centrality, and $y_{t}^{i}$ are model-specific variables like the emission standard of the model. Note 
that in all columns the upward trend remains highly significant. Based on columns (4) and (5) this upward trend is significant within the Eurozone and even larger outside. Inspection of columns (2) and (4) reveals that prices are on average the more dispersed the more upscale the car segment is. Columns (3) and (5) show that the increase in price dispersion during 20032011 is common to all car segments, but most pronounced in the upscale segments executive (E) and luxury (F). We conclude that the prevalence of price dispersion, and the overall upward trend in price dispersion are not driven by any single segment of the market, but instead reflect a characteristic of the entire European car market which calls for explanation.

[Table 1 about here.]

We now turn to model-specific real exchange rates, $r_{t}^{i, c}$. The upper panel of Figure 4 shows the distribution of real exchange rates relative to Germany, separately for each survey. We see that the distribution of real exchange rates is more spread out in 2011 than in 2003. Far from converging, pre-tax car prices in EU countries have actually drifted away from the pre-tax prices in Germany for mechanically identical cars. Looking at real exchange rates relative to the Netherlands in the lower panel, there is again no evidence of convergence over time. If anything, pre-tax prices have diverged.

[Figure 4 about here.]

A closer look at the data ${ }^{24}$ reveals that real exchange rates vary not only across country pairs but also across car models for the same pair of countries. Over time the real exchange rate averaged over car models seems to be quite stable for each country. An exception is the 2009 survey, where a number of countries exhibit large drops in their mean real exchange rates. Figure 4 shows the resulting massive increase in real exchange rate dispersion in 2009. These large deviations from parity have only partially decayed since then.

\subsection{Mean Reversion of Real Exchange Rates}

In this subsection we examine the transitional properties of the real exchange rate. For comparison of our results with studies of pre-2003 vintages of the data set we examine how quickly prices revert to their country-pair-specific mean real exchange rate after a shock. Fast mean reversion would imply that prices are not sticky, but would not necessarily entail reversion to a common price, not even in the long run.

\footnotetext{
${ }^{24}$ To conserve space we do not include tables of summary statistics by country and model in the paper. They are available upon request.
} 
We first regress the real exchange rate $r_{t}^{i, c}$ on country dummies. As expected given our previous results on price dispersion, almost all dummies are highly significant. We therefore reject absolute price convergence for European car prices, just as Crucini and Shintani (2008) do for consumer goods among cities across the world. Despite the EU Internal Market the law of one price (LOP) is grossly violated within Europe. We examine the causes of this finding in detail in the next section by decomposing these country fixed effects; here we examine the conditional convergence only, i.e. at what speed do prices converge to their country-specific mean? Using the residuals $\hat{r}_{t}^{i, c}$, i.e. $r_{t}^{i, c}$ net of the country mean, we model the auto-regressive property of the real exchange rate by

$$
\hat{r}_{t}^{i, c}=\rho_{1} \hat{r}_{t-1}^{i, c}+\rho_{2} \hat{r}_{t-1}^{E U R, i, c}+\beta x_{t}^{b(i)}+\gamma_{t}+\varepsilon_{t}^{i, c}+\kappa \varepsilon_{t-1}^{i, c},
$$

where $\gamma_{t}$ are time fixed effects and $\varepsilon_{t}^{i, c i i d} \sim\left(0, \sigma_{\varepsilon}^{2}\right)$. If a country is member of the Euro Area at time $t$, then $\hat{r}_{t}^{E U R, i, c}=\hat{r}_{t}^{i, c}$, and $\hat{r}_{t}^{E U R, i, c}=0$ otherwise. We estimate this dynamic panel by one-step GMM using the Arellano-Bover system estimator (Arellano and Bover, 1995; Blundell and Bond, 1998). Among the set of instruments we treat the VAT rate as exogenous. Weak evidence of MA(1) idiosyncratic errors makes us exclude variables lagged by less than three periods from the set of instruments in the semi-annual specifications.

[Table 2 about here.]

Table 2 reports the results for the real exchange rate vis-à-vis the Netherlands. The annualized autoregressive coefficients are small. They range from 0.15 to about 0.34 , which translates into a half-time of between 4 to 8 months. Deviations of real exchange rates from their country-specific mean are not persistent at all - the short implied half-time of less than one year is in line with many recent estimates based on disaggregated data (e.g. 11 months in Imbs, Mumtaz, Ravn, and Rey, 2005).

These autoregressive coefficients are smaller than the ones that Goldberg and Verboven (2005) find for a subset of five countries over the period 1970-2000 for the base countries Belgium and Germany, and close to the ones that Goldberg and Verboven (2004) find among 15 EU countries over the period 1993-2000 for the base country Netherlands. The speed at which temporary price shocks decay has not slowed down. It might well be that European integration since the late 1990s sped up the - already very quick - mean convergence within the EU. This mean, however, violates LOP as much today as 20 years ago.

Specification (3) shows that price differentials vis-à-vis the Netherlands of Euro Area members are less persistent than those of other EU members, but this difference is not sta- 
tistically significant. Relative prices in the Eurozone are - despite a fixed exchange rate - no stickier than in the rest of Europe.

We conclude from this analysis that the transitory behavior of real exchange rates within Europe is not the locus of price differentiation. ${ }^{25}$ Instead, market integration seems to be hampered by border effects, which - as in most studies - are left in this section as an unexplained fixed effect. As we saw in Section 3.4 price dispersion within Europe does not show any sign of shrinking. In the next section we turn our attention to these country effects, and in particular, why they do not disappear in spite of voluminous harmonization and competition regulation by the $\mathrm{EC}$.

\section{Determinants of Car Prices}

We start this section by describing our method of identifying the impact of bundling on car prices. After that, we examine the determinants of prices and of the real exchange rate within Europe.

\subsection{Empirical Approach}

Besides carving out differences in the pricing of car properties and general brand valuation across countries, we want to examine how differences in the option bundle across countries affect the price. Our data set provides a unique opportunity to do this. We have data on the availability and pricing of the following options: air conditioning (AC), automatic gearbox (AGB), anti-breaking system (ABS), power steering, airbags; and right-hand steering. Recall that $P_{t}^{i, c}$ and $r_{t}^{i, c}$ are already feature-adjusted using this information: they include all available options. However, we also know, for each model, which of these features is offered as standard in which country. In other words, although the models we compare are identical in terms of what the customer gets, they differ in terms of the menu of options available to the buyers in each country. Thus, for some country-model pairs, AC is part of the standard option bundle (and cannot be deselected). For others, it has to be actively selected for an extra charge, and the customer could also buy the car without AC. We therefore include in all regressions dummy variables that reflect the offered option bundle. The dummies indicate whether a given option is included as standard in the car's list price. These regressors

\footnotetext{
${ }^{25}$ Our data set is a short panel with a frequency change, and thus our estimates of an autoregressive coefficient should be taken with caution. Car prices change only infrequently, and are thus may not the best object for studying price stickiness.
} 
allow us to measure the effect of including an option as standard - alone, separate from the actual price of this option. The option dummies measure an effect that is solely based on a change in the menu of alternative offers, potentially combined with an unobserved change in presentation or positioning of the car within the market in question. ${ }^{26}$

\subsection{Determinants of Car Price Differences between Countries}

Which factors determine the price of a car model in Europe? To answer this question, we examine the relevance of model, brand and country properties for the pre-tax, feature-adjusted price, $P_{t}^{i, c}$ with the regression:

$$
P_{t}^{i, c}=\alpha_{t}+\beta_{1}^{i}+\beta_{2}^{c}+\beta_{3}^{b(i)}+\gamma_{1}^{c} x_{t}^{c}+\gamma_{2}^{c} y_{t}^{i}+\gamma_{3}^{c} z_{t}^{i, c}+\varepsilon_{t}^{i, c}
$$

Our interest focuses on the model-specific variables $y_{t}^{i}$ and $z_{t}^{i, c}$. The first group of regressors, $y_{t}^{i}$, comprises first and foremost the car's mechanical properties: engine size, engine power, fuel type, gearbox type, emissions ( $\mathrm{HC}, \mathrm{NO}_{x}$, particles), the model's published emissions rating, as well as its measured fuel consumption. ${ }^{27}$ The second group of regressors, $z_{t}^{i, c}$, includes dummy variables indicating whether a given option is included as standard in the car's price, as discussed in Section 4.1. Both groups of model-specific regressors contain several controls, such as warranty coverage and the availability of dealer services (roadside assistance, delivery). ${ }^{28}$ We also include the model's effective registration tax, which of course varies by country, as well as its market segment as defined in section 3.4 .

We account for variation at the country level by including population, GDP per capita, distance from the car's assembly plant (if in Europe, otherwise distance from port of entry), the rate of VAT, and the amount of tax on gasoline and diesel fuel as controls $x_{t}^{c}$. In the fixed effects specification we include model fixed effects and time dummies. In the random effects specifications we include time, country, and brand dummies.

\footnotetext{
${ }^{26} \mathrm{Not}$ all features vary in this way across countries. AC does, and to a lesser extent ABS and airbags as well, though not enough to allow for interaction terms with other variables. Power steering is almost always standard in our data, therefore we do not include a dummy variable for that feature. Right hand steering is country dependent across all models: standard in left-hand driving countries, and optional everywhere else. A dummy variable would therefore be picked up by country effects.

${ }^{27} \mathrm{CO}_{2}$ emissions are collinear with fuel consumption and thus omitted.

${ }^{28} \mathrm{By}$ the EU consumer directive, manufacturers must offer at least a two-year EU-wide standard warranty regardless of where the car was purchased. However they are free to offer longer coverage, and this might allow additional price-differentiation across countries. Similarly, roadside assistance services can conceivably be offered with geographic restrictions, and delivery charges may pertain only to dealerships within a certain country or group of countries. These factors could theoretically explain part of the log-difference in price; fortunately, we can control for them in our regressions.
} 
[Table 3 about here.]

[Table 4 about here.]

Table 3 presents the results of four variants of regression (3). The fixed effects regression in column 1 already uncovers some expected and some surprising features of the data. As one would expect, more powerful cars and cars with a larger engine are more expensive. In contrast, higher emissions of $\mathrm{HC}, \mathrm{NO}_{x}$, and particles depress, ceteris paribus, the price. An extended warranty has no significant impact on price, all else equal. The inclusion of options as standard entails a "bundle discount". The role of fuel consumption is somewhat surprising. Since high fuel consumption increases the car's operating costs and the isomorphic $\mathrm{CO}_{2}$ emissions increase registration and/or operating taxes, one might expect a reduction in price. Our regressions show, however, that another effect dominates. Cars with high fuel consumption are often cars that target drivers which value "sportive" acceleration more than fuel- and tax-efficient engines. Fuel consumption appears to proxy for this, and thus increases, ceteris paribus, the price.

Turning to the country controls, in the lower part of the table we see that countries with higher GDP per capita pay higher prices for the same car. Distance from the nearest assembly location does not play a big role for prices in the European car market, implying a small role for distribution costs in price determination, at least those costs that are correlated with geographical distance. The effect of tax rates is not straightforward. The model-specific registration tax tends to lower the car price, in line with monopolistic price setting, but only insignificantly. Instead general taxes, not specific to a car model, such as fuel tax and VAT, increase the price. A possible explanation of this effect might be that in high-tax countries cars, especially inefficient cars, are to some extent a positional good (Veblen good). A deeper look (see Appendix C.2) uncovers that the positive relationship indeed stems mostly from the segments D, E and G, i.e. cars that might serve as status symbol.

Columns 2 to 4 of Table 3 present the results of the random effects specifications. Column 2 includes model-specific regressors that are constant over time, and column 3 includes additionally country-specific cubic time trends, ${ }^{29}$ and column 4 adds country-interactions to the AC dummy. Neither the sign and significance of individual coefficients nor the overall explanatory power are greatly affected by the switch to random effects. We continue with random effects, for reasons that will become apparent in the next subsection, namely, that we want to examine interactions among observed and unobserved effects. The random effects specification allows us to extract the effect of car features that do not vary over time.

\footnotetext{
${ }^{29}$ The country-specific time trends are not reported in the table, but discussed in Appendix C.3
} 
[Table 5 about here.]

We report the brand effects of column 3 separately in Table 5 , ordered by size. The ordering is strikingly intuitive. For a car with identical features and options, the price of a Mercedes is more than $€ 10000$ higher than the price of a Suzuki. High-volume producers such as Toyota and Volkswagen command almost identical prices, all else equal. Comparing columns 2 and 3 also shows that all of the population and GDP dynamics can be picked up by country-specific cubic time trends.

As for mechanical properties, an automatic gearbox and a diesel engine are associated with a higher price on average. The coefficients on market segments shown separately in Table 4 increase monotonically with the market segment, as we would expect.

Overall, random effects and fixed effects models give the same results. Importantly for our purposes, the coefficients for the included options are consistently negative and strongly significant. They show evidence of a "bundle discount", that is, the price of a car with an optional feature will be lower if that feature is offered as part of the standard bundle of features. These effects turn out to be very useful for the purpose of price discrimination, as we show in the next section.

[Figure 5 about here.]

In order to explore country heterogeneity at more detail we expand the specification of column 3 in Table 3 further by interacting all variables (except the country-related ones) with country dummies. Particularly interesting is the variation of segment effects across countries. Table 4 and Figure 5 confirm that throughout Europe the rule "The higher the segment, the higher the price premium." holds. In all European countries the premium increases monotonically from the mini car segment (A), via small, medium, large (D), and executive, to luxury cars $(\mathrm{F})$. Multipurpose cars are approximately at the executive car price level, which is the reason for category E not being visible in Figure 5 for some countries. The prices of the Segments A to D are very close. In contrast, luxury cars constitute a completely different price segment. In Finland, luxury cars appear to face the most elastic demand within Europe. Most importantly, there is considerable heterogeneity in terms of segment price dispersion. For example, the price difference between the adjacent segments executive and large cars in Denmark is larger than the price difference between executive and mini cars in Sweden - i.e. between cars four segments apart.

The variation across countries highlighted in Figure 5 for the case of segments is typical. Coefficients on most car features vary considerably between countries in the expanded 
specification. This implies that pricing-to-market efforts on the part of manufacturers can be traced to particular car features. Next, we examine model-specific real exchange rates directly.

\section{Bundling}

The empirical results so far explained what determines price differences between countries. The more puzzling question is, however, how these price differentials can persist in an integrated, competitive market like the EU? We show in this section that bundling by manufacturers can explain these differentials. First, we illustrate in a simple model the incentives for manufacturers to use bundling to differentiate products between countries. Then, we show empirical evidence on the heterogeneous pricing of car features in and outside of bundles across European countries.

\subsection{A Model of Price Discrimination Within and Across Borders}

In this subsection we explore when the bundling choices of car manufacturers uncovered in the previous section are optimal. That is, we derive conditions under which manufacturers optimally offer a menu of optional features in some countries but only a pre-installed set of features in other countries.

In the model, car customers in some countries disagree more than in other countries as to the value of a certain car feature, for example installed air conditioning (AC). In countries where some customers' willingness to pay for this particular feature is high, the manufacturer may charge a high price for the option, so that only the high-value customers will choose to buy the car with AC installed, while the low-value customers will buy the car without AC. This is optimal if the gains from charging the high-value customers for the option outweigh the loss of revenue incurred by not selling the option to the low-value customers. In these countries, offering AC as standard would not be optimal because it would force the manufacturer to sell the car at the same price to both groups of customers, leaving a large consumer surplus to the high-value customers. In other countries, however, the difference among customers with regards to the willingness to pay for $\mathrm{AC}$ might not be as large, therefore separating the customers in the way described might reduce profits instead of raising them. The manufacturer will then offer AC as standard in those countries, but at a lower price since it has to appeal to the entire customer base, rather than to the high-value customers only. This pricing scheme is limited, however, by the ability of customers to purchase across borders. 
Consider a monopolistic car manufacturer selling a particular car in two countries, A and B. Assume that consumer types can be defined by the vector $(\theta, \gamma)$, where $\theta$ is the willingness to pay for the car, $\gamma$ the willingness to pay for a feature option installed in the car by the manufacturer (say, AC). Based on their willingness to pay for the feature, consumers in both countries are divided in two groups:

1. Type 1 consumers, with $\left(\theta, \bar{\gamma}_{X}\right)$, of whom there are $\bar{N}_{X}$ in country $X \in\{A, B\}$, and

2. Type 2 consumers, with $\left(\theta, \underline{\gamma}_{X}\right)$, of whom there are $\underline{N}_{X}$ in country $X \in\{A, B\}$,

where $\bar{\gamma}_{X}>\underline{\gamma}_{X}$ for any country $X$. A consumer purchasing the car in the other country has to pay an additional (transaction) $\operatorname{cost} c$. For simplicity we assume that the cost of producing the car with or without the option is zero and therefore the monopolist will want to sell as many cars as possible. In particular, the monopolist will always prefer to sell the car with the option installed, because he can ask for a higher price without increasing costs. However he may choose to sell it to some customers without the option if in so doing he can sell it to other customers with the option installed at a higher price, thereby increasing his profits. We will assume throughout that consumers will choose to buy the car if indifferent, and further that when indifferent between two versions of the car, they will choose the car with the option installed. Also assume without loss of generality that $\underline{\gamma}_{A}>\underline{\gamma}_{B}$, so that type 2 consumers in Country A place a higher value on the option.

To keep notation at a minimum we assume in the following

$$
\bar{\gamma}_{A}>\bar{\gamma}_{B}>\underline{\gamma}_{A}>\underline{\gamma}_{B}
$$

and that $\theta$ is sufficiently large. These assumptions could easily be lifted at the expense of an even wider array of pricing and bundling combinations.

The monopolist can choose among the following pricing and selling schemes:

Scheme I (Symmetric Bundling) - Sell in both countries only with the installed option, at price $p_{A}^{W I T H}=\theta+\underline{\gamma}_{A}-\varepsilon_{A}^{I}$ in country A, and at price $p_{B}^{W I T H}=\theta+\underline{\gamma}_{B}$ in country B. All consumers buy under our assumptions. The country-specific discount $\varepsilon_{A}^{I}$ is chosen by the monopolist to dissuade consumers from buying in another country at a lower price. Consumers buy the car in their own country if the discount is large enough so that country A consumers are not tempted to shop abroad, but not so large as to cause country B consumers 
to shop in country A. The discount $\varepsilon_{A}^{I}$ then satisfies

$$
\underline{\gamma}_{A}-\underline{\gamma}_{B}+c \geq \varepsilon_{A}^{I} \geq \max \left(\underline{\gamma}_{A}-\underline{\gamma}_{B}-c, 0\right)
$$

The expression $\underline{\gamma}_{A}-\underline{\gamma}_{B}-c$ need not be large, indeed it could well be negative, implying that $\varepsilon_{A}^{I}$ may be quite small. Assuming the monopolist chooses $\varepsilon_{A}^{I}$ such that the above condition holds, its profit is ${ }^{30}$

$$
\Pi_{I}=\left(\bar{N}_{A}+\underline{N}_{A}\right)\left(\theta+\underline{\gamma}_{A}-\varepsilon_{A}^{I}\right)+\left(\bar{N}_{B}+\underline{N}_{B}\right)\left(\theta+\underline{\gamma}_{B}\right)
$$

Scheme II (No Bundling) - Sell the car in both countries with and without the option, at the following prices: $p_{A}^{\text {WITH }}=\theta+\bar{\gamma}_{A}-\varepsilon_{A}^{I I}, p_{B}^{\text {WITH }}=\theta+\bar{\gamma}_{B}, p_{A}^{\text {WITHOUT }}=p_{B}^{\text {WITHOUT }}=\theta$. Here the monopolist is able to increase his profit from type 1 consumers in both countries (assuming again that $\varepsilon_{A}$ is chosen appropriately, i.e.

$$
\varepsilon_{A}^{I I} \geq \max \left(\bar{\gamma}_{A}-\bar{\gamma}_{B}-c, 0\right)
$$

to dissuade cross-border purchases), but can only sell the car to type 2 consumers without the installed option, thereby losing some profits as well. The profits are therefore

$$
\Pi_{I I}=\left(\underline{N}_{A}+\underline{N}_{B}\right) \theta+\bar{N}_{A}\left(\theta+\bar{\gamma}_{A}-\varepsilon_{A}^{I I}\right)+\bar{N}_{B}\left(\theta+\bar{\gamma}_{B}\right)
$$

Scheme III (Asymmetric Bundling) - Sell the car in country A only with the option, but sell both versions in country B. Prices will be: $p_{A}^{W I T H}=\theta+\underline{\gamma}_{A}, p_{B}^{W I T H}=\theta+\bar{\gamma}_{B}-\varepsilon_{B}$, $p_{B}^{W I T H O U T}=\theta$. Here the monopolist essentially forces type 2 consumers in country B to buy the car without the option installed (same result as in Scheme II), but type 2 consumers in country A now buy the car with the option (same result as in Scheme I). Type 1 consumers in country $B$ are given a discount $\varepsilon_{B}$ which satisfies

$$
\varepsilon_{B} \geq \max \left(\bar{\gamma}_{B}-\underline{\gamma}_{A}-c, 0\right)
$$

to dissuade them from cross-border purchases. Profits are now be given by

$$
\Pi_{I I I}=\underline{N}_{B} \theta+\bar{N}_{B}\left(\theta+\bar{\gamma}_{B}-\varepsilon_{B}\right)+\left(\bar{N}_{A}+\underline{N}_{A}\right)\left(\theta+\underline{\gamma}_{A}\right) .
$$

\footnotetext{
${ }^{30} \mathrm{~A}$ variation of Scheme I where the car is sold in Country B at a higher price $p_{B}^{W I T H}=\theta+\bar{\gamma}_{B}-\varepsilon_{B}$ with discount $\varepsilon_{B} \geq \bar{\gamma}_{B}-\underline{\gamma}_{A}-c$, is more profitable if $\underline{N}_{B} \theta>\bar{N}_{B}\left(-\underline{\gamma}_{A}+\bar{\gamma}_{B}-c\right)$. It is dominated by selling to all customers (see Scheme III below) if $\theta$, the margin on the car itself, is sufficiently large.
} 
We now examine under which conditions asymmetric bundling is optimal. We examine two polar scenarios: first a scenario where markets are naturally separated, and then a scenario where arbitrage opportunities abound.

Separated Markets - Suppose that markets are separated by a sufficiently high border cost, i.e. $\bar{\gamma}_{A}-\underline{\gamma}_{B} \leq c$, so that arbitrage is not possible and thus $\varepsilon_{A}^{I}=\varepsilon_{A}^{I I}=\varepsilon_{B}=0$.

Asymmetric bundling (Scheme III) is preferable to no bundling (Scheme II) if the profits gained from selling the option to type 2 customers in country A are larger than the profits lost by selling the option at a lower price to type 1 customers in country A. That is, if

$$
\underline{N}_{A} \underline{\gamma}_{A}>\bar{N}_{A}\left(\bar{\gamma}_{A}-\underline{\gamma}_{A}\right)
$$

Asymmetric bundling (Scheme III) is preferable to symmetric bundling (Scheme I) if the profits gained from selling the option to type 1 customers in country B at a higher price are larger than the profits lost by not selling the option to type 2 customers in country B. That is, if

$$
\bar{N}_{B}\left(\bar{\gamma}_{B}-\underline{\gamma}_{B}\right)>\underline{N}_{B} \underline{\gamma}_{B}
$$

Therefore, we would expect to observe asymmetric bundling if countries are very different in:

- the relative size of customer segments, in our scenario $\underline{N}_{A}>>\bar{N}_{A}$ and $\underline{N}_{B}<<\bar{N}_{B}$,

- the heterogeneity of their customers, in our scenario $\bar{\gamma}_{A}-\underline{\gamma}_{A}$ small, $\bar{\gamma}_{B}-\underline{\gamma}_{B}$ large, and

- the valuation for the option by the lower segment, in our scenario $\underline{\gamma}_{A}$ large, $\underline{\gamma}_{B}$ small.

This is in particular satisfied in the extreme case $\bar{\gamma}_{A}=\bar{\gamma}_{B}=\underline{\gamma}_{A}=\underline{\gamma}_{B}+c$.

Open Markets - Suppose now that $\bar{\gamma}_{A}-\bar{\gamma}_{B}>c, \bar{\gamma}_{B}-\underline{\gamma}_{A}>c$, and $\underline{\gamma}_{A}-\underline{\gamma}_{B}>c$, so that arbitrage constrains the sustainable prices.

In this case the monopolist chooses in each scenario the minimum discount such that the inequality constraints (5), (7), and (9) bind. Therefore the profit in Scheme I given by Equation (6) becomes

$$
\Pi_{I}=N\left(\theta+\underline{\gamma}_{B}\right)+\left(\bar{N}_{A}+\underline{N}_{A}\right) c .
$$

Profit in Scheme II (Equation 8) becomes

$$
\Pi_{I I}=N \theta+\left(\bar{N}_{A}+\bar{N}_{B}\right) \bar{\gamma}_{B}+\bar{N}_{A} c
$$


and in Scheme III (Equation 10) it is now

$$
\Pi_{I I I}=N \theta+\left(\bar{N}_{A}+\bar{N}_{B}+\underline{N}_{A}\right) \underline{\gamma}_{A}+\bar{N}_{B} c
$$

Comparing again schemes, we find that asymmetric bundling (Scheme III) is preferable to no bundling (Scheme II) if

$$
\underline{N}_{A} \underline{\gamma}_{A}>\bar{N}_{A}\left(\bar{\gamma}_{B}-\underline{\gamma}_{A}+c\right)+\bar{N}_{B}\left(\bar{\gamma}_{B}-\underline{\gamma}_{A}-c\right)
$$

The term on the left reflects the additional AC sales to the lower customer segment in $\mathrm{A}$ under asymmetric bundling. The terms on the right reflect the countervailing losses. The first term captures the direct effect, that the upper customer segment in A now pays less for AC $\left(\underline{\gamma}_{A}\right.$ instead of $\left.\bar{\gamma}_{B}+c\right)$, because the bundle is cheaper than its components. The second term captures the indirect effect, that the upper customer segment in B now benefits from arbitrage with $\mathrm{A}\left(\underline{\gamma}_{A}+c\right.$ instead of $\left.\bar{\gamma}_{B}\right)$. Compared to $(11)$ two things change: first, the sustainable price differences become smaller, and second, the spillover to the other market shows up in the last term.

Analogously, asymmetric bundling (Scheme III) is preferable to symmetric bundling (Scheme I) if

$$
\bar{N}_{B}\left(\underline{\gamma}_{A}-\underline{\gamma}_{B}+c\right)+\left(\bar{N}_{A}+\underline{N}_{A}\right)\left(\underline{\gamma}_{A}-\underline{\gamma}_{B}-c\right)>\underline{N}_{B} \underline{\gamma}_{B}
$$

The term on the right reflects the lost AC sales to the lower customer segment in B under asymmetric bundling. The terms on the left reflect the countervailing gains. The first term is the direct effect, that the upper customer segment in B can no longer free-ride on the low bundled AC price and can at best import a bundled car from A $\left(\underline{\gamma}_{A}+c\right.$ instead of $\left.\underline{\gamma}_{B}\right)$. The second term captures the indirect effect, that customers in A cannot obtain a cheap bundled $\mathrm{AC}$ in B any more $\left(\underline{\gamma}_{B}+c\right)$ but must instead buy in the home market $\left(\underline{\gamma}_{A}\right)$.

Combining the two inequalities (13) and (14) and rearranging we get that asymmetric bundling is optimal if

$$
\left(\bar{N}_{A}+\bar{N}_{B}+\underline{N}_{A}\right) \underline{\gamma}_{A}>\left(\bar{N}_{A}-\bar{N}_{B}\right) c+\max \left[\left(\bar{N}_{A}+\bar{N}_{B}\right) \bar{\gamma}_{B} ;\left(\bar{N}_{A}+\bar{N}_{B}+\underline{N}_{A}+\underline{N}_{B}\right) \underline{\gamma}_{B}+\underline{N}_{A} c\right] .
$$

The term $\left(\bar{N}_{A}-\bar{N}_{B}\right) c$ captures the tradeoff between domestic freeriding of the upper customer segment if $\mathrm{AC}$ is bundled and international arbitrage. Given the assumed ordering of preferences (4) a high $\bar{N}_{A}$ gives the manufacturer an incentive to price the upper customer segment in A separately to extract consumer rent. A higher $c$ shuts down international arbi- 
trage opportunities, thus a higher $c$ makes bundling in A less attractive for the manufacturer. A high $\bar{N}_{B}$ further increases the manufacturer's incentive to price the upper customer segment in A separately, because it prevents arbitrage by customers in country B. A higher $c$, however, makes this arbitrage less attractive for customers in the first place. Therefore a higher $c$ weakens this second incentive and makes bundling in A less costly for the manufacturer. In our simple model the magnitude of these two effects is parametrized by $\bar{N}_{A}$ and $\bar{N}_{B}$. If $\bar{N}_{A}>\bar{N}_{B}$, the first effect dominates, and a decrease in arbitrage cost leads to an increase in asymmetric bundling.

The conditions under which asymmetric bundling occurs are similar to the ones that obtain under separated markets: Asymmetric bundling is likely to be observed if the difference between high and low valuations is relatively small in country A and relatively large in country $\mathrm{B}$, and/or if the low valuation in country $\mathrm{A}$ is high relative to that of country $\mathrm{B}$, and/or if the ratio of type 1 to type 2 consumers in country $A$ is small relative to the ratio in country B.

Our simple model established the profitability of PTM for one manufacturer, and the conditions indicate that different bundling strategies can coexist in a given market at the same time. Indeed Vaubourg (2006) shows that in a duopoly setting equilibria exist in which the one firm sells only bundles, whereas the other firms sells also a separate component.

Whereas the one-good case presented here is easy to solve, optimality of a bundle price schedule for multi-product firms is hard to establish. In fact, the profit-maximizing pricing strategy for a multi-product monopolist might require randomization of bundle assignments (see e.g. Manelli and Vincent, 2006). ${ }^{31}$

\subsection{Bundling and Car Price Differentials}

The model in the previous section shows that there are many market settings in which bundling is an attractive strategy for the manufacturer. Unsurprisingly, therefore, the countries in our sample differ widely on whether and what bundles are offered. In this subsection explore how the bundling of car features affects relative prices in Europe.

[Table 6 about here.]

\footnotetext{
${ }^{31}$ Many studies for specific market settings exist, often ruling out the possibility of simultaneously offering a bundle and its components separately, as for example in Fang and Norman (2006). Liao and Tauman (2002) provide in a table a short overview of studies by market setting. Furthermore, manufacturers might use bundling not only directly to segment the market, but might benefit also from easier collusion in presence of bundling (Spector, 2007).
} 
We return to the country-specific coefficients from the regression in column 4 of Table 3. The model in the previous section implies that the price charged to customers when AC is bundled resembles $\theta+\underline{\gamma}$. As noted earlier, when $\mathrm{AC}$ is unbundled, we calculate the total car price by adding the cost of $\mathrm{AC}$ to the base price of the car. In the unbundled case $\mathrm{AC}$ is selected by the upper customer segment only, and so the price reflects $\theta+\bar{\gamma}$. Combined, the coefficients on AC bundling mirror $\underline{\gamma}-\bar{\gamma}$ in our model. They are shown in Table 6 . The estimated price of AC differs by more than 1700 EUR between the upper and lower customer group in Romania. In contrast, in southern countries like Greece, Italy and Spain the difference is indistinguishable from zero, indicating that $\mathrm{AC}$ is considered a necessity in these countries.

\section{[Table 7 about here.]}

[Figure 6 about here.]

The more northern a country, the more the AC feature is presumably considered luxurious and therefore its inclusion may target a narrowing range at the top of the customer segments. Its valuation by the now smaller top segment then increases. The upper panel of Figure 6 supports this conjecture: the AC bundling discount in northern countries (measured by the latitude of the capital city) is generally larger. Table 7 reveals that the correlation of -0.43 is driven by a simultaneously decreasing $\underline{\gamma}$ and a increasing $\bar{\gamma}$ as we go further north. Besides the positive correlation with latitude, Table 7 reveals a weak correlation of price spread with inequality as measured by the Gini Index. In less equal countries we expect that the valuation spread between the lower segment and the upper segment would be relatively large, leading to an increased bundling discount. The scatter plot in the lower panel of Figure 6 shows that this correlation is indeed present in the data. ${ }^{32}$

\section{[Table 8 about here.]}

Using the mean of the country-specific covariates population, GDP per capita, VAT, and petrol tax and their corresponding coefficient estimates from Table 3 together with the estimated country fixed effects, we are able to put the within-country price difference between segments in relation to the price differences across countries. In Table 8 we report the resulting ordering of customer segments with respect to AC across Europe reflected in car

\footnotetext{
${ }^{32}$ The Gini coefficients are averages over annual values from 2003 to 2011 provided by Eurostat. The regression of the price difference on the Gini coefficient and latitude of the capital for each of the 27 countries gives similar results (Adj. $R^{2}=0.14$ ).
} 
prices. The prices in this table should only be interpreted relative to each other, because all model-specific effects were removed. The premium that AC demands from the upper customer segment in Germany above the the lower segment from the UK is more than 4000 EUR. Interestingly, the upper customer segments of several countries are priced below the lower customer segments of another country. For example, the lower customer segment in Finland pays more than 800 EUR more than the upper segment of the UK. Germany, Belgium, and the Netherlands show even larger differences relative to the UK. The table shows a sophisticated and large price spread not only between countries but also between customer segments within and across countries. We emphasize that these spreads are based on AC bundling alone, so that bundling across multiple features in likely to support even larger price differences.

\section{Real Exchange Rates}

The findings in the previous sections result from bona fide cross-country price differentiation. They are not driven by aggregation effects that may show up due to the different composition of models offered for sale across countries and survey periods. To see that, we present in Table 9 the results of regressing model-specific real exchange rates, $r_{t}^{i, c}$, on the same groups of variables which we used in previous sections, with some necessary changes. Recall that the real exchange rate is defined for mechanically identical models sold in different countries. Since we get similar results to those of the price regressions, we can be certain that aggregation effects do not play an important role. The estimated equation is:

$$
r_{t}^{i, c}=\alpha_{1}^{i}+\alpha_{2}^{c}+\beta_{1}^{c} x^{b(i), c}+\beta_{2}^{c} x_{t}^{i}+\beta_{3}^{c} y_{t}^{i, c}+\beta_{4}^{c} z_{t}^{c}+\gamma_{t}+\varepsilon_{t}^{i, c} .
$$

Our main interest now lies with the variables grouped under $y_{t}^{i, c}$. These are dummy variables indicating, for each model sold in any given country, whether the mode of sale of each the car's features in that country is similar or different to the mode of sale of that feature for that model in the Netherlands. For each feature, we define four dummy variables to cover all possible combinations: either the feature is standard in both countries, or it is standard in the Netherlands (NL) but optional in the other country (OC), or it is standard in the other country but optional in the Netherlands, or it is optional in both countries. We then omit the dummy variable for the combination which is most common in the data - usually, that the feature is included as standard in both countries. In our preferred specifications, we interact these variables with country dummies and with country-level variables. 
The country-level group of regressors $z_{t}^{c}$ includes the same variables as before, but are now defined relative to the base country Netherlands. For example, the VAT variable now measures the difference between the VAT of the country where the model is sold, and the VAT effective in the Netherlands at that time. The model-level group of variables $x_{t}^{i}$ are the car's mechanical properties, defined as before, and the car's segment. We include brand centrality $x^{b(i), c}$ as well, which is a country-brand measure of demand. The more central a particular brand is in a given country relative to the Netherlands, the more competition it faces there, again relative to the Netherlands, and therefore it enjoys less monopoly power. Further, we include interaction terms for "home bias". For example, Peugeot cars historically were developed and produced in France, and may command a certain loyalty among French car buyers, quite separate from the actual assembly location. Finally, we control throughout for differences between the Netherlands and other countries in warranty coverage, roadside assistance service, and cost of delivery. Our random effects regressions also include country, brand, and time dummies.

[Table 9 about here.]

Table 9 presents the regression results for the model-specific real exchange rates. Columns 1 and 2 show a specification analogous to columns 1 and 2 of the price regression in Table 3, with fixed effects or random effects included, respectively. As in the price regression, we see that the coefficients do not change much between the fixed effects and random effects specifications. We prefer the random effects specification because it allows us to observe the effects of particular variables by country, as we do in the regression shown in column 5. The regression shown in column 3 includes more controls relative to column 2 , but no interactions. Column 4 adds interactions with some country variables, details of which will be discussed below. Looking across columns, we see that most coefficients are stable in sign and significance. Comparing these results to those presented in Table 3, we see that variables have similar signs and significance, as we would expect.

We now turn to the variables indicating the combinations of standard vs. optional inclusion of features. For each feature - AC, ABS, and airbag - the default is always the same, namely that the feature is included as standard in the Netherlands as well as in the other country in question. The coefficients shown in columns 1 to 3 of the table then are the average effect across countries of choosing a different combination than the default. We see that real exchange rates for models where AC is optional in both countries are not significantly different than real exchange rates for the default models where AC is included as standard in 
both countries. However models where AC is optional only in the Netherlands are about $8 \%$ more expensive in the Netherlands on average relative to the default, depending on the exact specification. Likewise, models where AC is included only in the Netherlands are about $8 \%$ cheaper in the Netherlands, again relative to the default. We interpret these results in the following way: cars are not significantly differently priced in European countries relative to the Netherlands if they are sold in the same way in both countries, i.e. either with AC included as standard in both countries or AC priced separately in both countries. However, cars are priced differently when they are sold in different ways, even though, recall, the cars are mechanically identical. Netherlands turns out to be also a typical European country in terms of the size of the bundling discount, because its discount is similar in magnitude to the average bundling discount in Europe. ${ }^{33}$

Several EU countries (Slovenia, Cyprus, Malta, Slovakia, and Estonia) have adopted the euro within the period covered by our sample. We include a eurozone dummy to see whether adopting the euro has an effect on the model-specific real exchange rate. It turns out that it does: countries adopting the euro experience a drop of about $1 \%$ in their real exchange rates on average, a result that is stable across specifications. The controls for home demand effects reveal that in some countries real exchange rates for their "home" brands are indeed significantly different from real exchange rates for the same brands sold in other European countries. For example, French brands such as Peugeot and Renault are on average about 6\% more expensive when sold in France relative to the price of the same French brands sold outside of France. German and Swedish brands, however, are less expensive in their "home" countries.

We see, as we would expect from the results already presented, that model-specific real exchange rates are significantly affected by country-level variables, even after the inclusion of country, brand, and time dummies. In other words, price differentiation across country borders can be associated with a number of country-level variables, whose signs and statis-

\footnotetext{
${ }^{33}$ The coefficients for ABS show a very similar pattern: there is no significant difference in prices whether ABS is included as standard in both countries (the default) or priced separately in both countries. However, if included as standard in the Netherlands only, it becomes about $4 \%$ cheaper in the Netherlands on average, again relative to the default (column 3). Models where ABS is optional in the Netherlands only are about $4 \%$ more expensive in the Netherlands on average. The coefficients for airbag tell a different story. Note first that the combination for models where an airbag is included in the other country but optional in the Netherlands is missing. That is because this set is empty in our data. The opposite case, where an airbag is included in the Netherlands only, is never significantly different from the default where an airbag is included as standard in both countries. However the combination where an airbag is priced separately in both countries is associated with an almost $8 \%$ difference in price, relative to the default. It appears that in other countries, whether an airbag is included as standard or not does not matter much on average for pricing purposes, however in the Netherlands it does.
} 
tical significance are quite stable across specifications. The coefficient signs are broadly the same as in the price regressions. ${ }^{34}$

Column 4 presents a regression similar to that in column 3, with the addition of interaction terms for country characteristics relative to the Netherlands - population, GDP per capita, and the VAT rate - and model feature dummies indicating whether AC is standard or optional. We run this regression to see whether the determinants of price differentiation across countries, as seen in columns 1 through 3, reinforce each other. It turns out that in some cases they do, and the direction is always such that differences in how a car is sold magnify the differentiation effect of the country variable. Table 10 shows the coefficients for these interaction terms in the column 4 regression, for those interactions where we have enough variation in the data. We see that, for example, the positive effect of an increase in a country's GDP per capita on the model-specific real exchange rate — which we estimated at $0.22 \%$ per 1000 PPP euros — increases by a further $0.12 \%$ per 1000 PPP euros if AC is sold as an option in that country whereas in the Netherlands it is sold as standard. Similarly, the effect of a larger population on the real exchange rate is magnified if AC is optional in that country but standard in the Netherlands. As expected, when AC is sold as optional in both countries there is no such effect.

[Table 10 about here.]

Column 5 of Table 9 presents the regression results when we interact the AC dummy variables with country dummies, in order to observe whether these effects differ by country, as they do in the price regressions. Table 11 shows these country-specific coefficients.

[Table 11 about here.]

\footnotetext{
${ }^{34}$ For example, an increase of a country's population by one million, keeping the Netherlands' population constant, reduces the real exchange rate by about $0.4 \%$ in the column 3 regression. We interpret this number as the cross-country average effect of population increases over time. Similarly, we see a positive effect on the real exchange rate of a higher per capita GDP (PPP adjusted), a higher VAT rate, a higher petrol tax, and a higher diesel tax, regardless of whether or not the model in question has a diesel engine. Again we interpret these effects as the cross-country average effect of changes over time. In contrast, the effective registration tax is always insignificant, implying that the effects of varying registration taxes across countries are completely absorbed by the country dummies. Lastly, the minimum distance variable, measuring for each model the distance to the nearest assembly location for the country in question relative to that distance for the Netherlands, is consistently negative, though not always significant: an increase of 1,000 km leads to a drop of less than $1 \%$ in the real exchange rate. Because distances are by definition constant, except in the relatively rare case when the assembly location of a model changes, our interpretation is that within brands, models which are assembled further away, relative to the distance from the Netherlands, are not more expensive on average, all else equal. To the extent that transportation costs are distance-related, these do not seem to be important determinants of relative prices.
} 
We find that the price markup on an unbundled AC varies by more than $10 \%$ among countries. It ranges from about zero (Greece, France) to more than 13\% (Sweden, Malta). For example, unbundling $\mathrm{AC}$ on a model sold in Belgium increases the price in Belgium by $11.4 \%$, whereas the same comparison for Hungary yields only a $5 \%$ price difference. We also find that when $\mathrm{AC}$ is unbundled in the Netherlands as well as in the other country, the real exchange rate tends to be insignificantly different from the base case where $\mathrm{AC}$ is bundled in both countries. This holds across most countries, with the exception of Cyprus, Malta, and Italy (negative effect), and Estonia (positive effect). In general, if the mode of sale of the AC feature is similar across countries we don't see a significant effect on the real exchange rate, except where weather-related preferences are relatively strong.

\section{Conclusion}

With this paper we expand our understanding of international price differences on three fronts:

First, we construct a rich data set of car prices in Europe which allows for true applesto-apples price comparisons. We show that pricing-to-market is pervasive in the European car market. Model-specific real exchange rates vary significantly both across and within countries. This is true both within the euro area and for the EU as a whole.

Second, we show that, whereas reversion to a country-specific mean is fast, there is little evidence of absolute price convergence. The European Commission (EC) recently revised the block exemption regulation governing the European car market, based on the notion that car prices within Europe have converged (European Commission, 2008). Using official EC data, we find only very limited evidence for this. It might be that the claimed convergence is a result of convergence in the car specifications reported to the EC over the years of the survey. When controlling for car features and correcting obviously erroneous data the convergence disappears. Pricing-to-market of passenger cars in Europe is very much an ongoing phenomenon, as of the year 2011.

Third, and perhaps most importantly, our results clearly show that car features are priced very differently throughout Europe. Manufacturers appear to build on differences in consumer preferences and consumer composition among European countries to tailor car-feature bundles to each market. This versioning of car models across Europe seems to go some way towards negating the effects of market integration in bringing prices closer together. In particular, we identify car features (like AC) which are a likely basis for active price differen- 
tiation by manufacturers. Differences in bundling of these features across countries explain differences in relative prices of $10 \%$ and more among EU countries. In order to reduce price differentiation at the border, EU competition policy will have go beyond regulating market access and removing administrative barriers. As already Adams and Yellen (1976) have suggested, it has to ensure a "competitive supply of each decomposable good separately" (Adams and Yellen, 1976, p.497f). This requires in our point of view mandatory unbundling of non-essential car components (such as GPS, audio, AC) and openly accessible interfaces, similar to the forced unbundling of Microsoft's Internet Explorer from its operating system. Otherwise, market segmentation along administrative barriers will just be replaced by market segmentation along country-specific bundles. Whereas the latter is more sophisticated, it affects competition in just the same way.

\section{References}

Adams, W. J., Yellen, J. L., 1976. Commodity bundling and the burden of monopoly. Quarterly Journal of Economics 90 (3), 475-498.

Alessandria, G., Kaboski, J. P., 2011. Pricing-to-market and the failure of absolute PPP. American Economic Journal: Macroeconomics 3 (1), 91-127.

Arellano, M., Bover, O., 1995. Another look at the instrumental variable estimation of error-components models. Journal of Econometrics 68 (1), 29-51.

Asplund, M., Friberg, R., Wilander, F., 2007. Demand and distance: Evidence on cross-border shopping. Journal of Public Economics 91 (1-2), 141-157.

Atkeson, A., Burstein, A., 2008. Pricing-to-market, trade costs, and international relative prices. American Economic Review 98 (5), 1998-2031.

Auer, R. A., Jan 2013. Product heterogeneity, cross-country taste differences, and the consumption home bias. Working Papers 13.01, Swiss National Bank, Study Center Gerzensee.

Baffes, J., 1991. Some further evidence on the law of one price: The law of one price still holds. American Journal of Agricultural Economics 73 (4), 1264-1273.

Berman, N., Mayer, T., Martin, P., 2012. How do different exporters react to exchange rate changes? Quarterly Journal of Economics 127 (1), 437-492.

Blundell, R., Bond, S. R., 1998. Initial conditions and moment restrictions in dynamic panel data models. Journal of Econometrics 87 (1), 115-143.

Broda, C., Weinstein, D. E., 2008. Understanding international price differences using barcode data. Working Paper 14017, National Bureau of Economic Research.

Burstein, A. T., Neves, J. C., Rebelo, S., 2003. Distribution costs and real exchange rate dynamics during exchange-rate-based stabilizations. Journal of Monetary Economics 50 (6), 1189-1214.

Cavallo, A. F., Neiman, B., Rigobon, R., 2012. Product introductions, currency unions, and the real exchange rate. Working Paper 18563, National Bureau of Economic Research. 
Corsetti, G., Dedola, L., 2005. A macroeconomic model of international price discrimination. Journal of International Economics 67 (1), 129-155.

Crucini, M. J., Shintani, M., 2008. Persistence in law of one price deviations: Evidence from micro-data. Journal of Monetary Economics 55 (3), 629-644.

Day, J. A., Smith, L., Neufeld, R., Gerstein, I. R., February 2013. The Canada-U.S. price gap ( $16^{\text {th }}$ report). Report of the Standing Senate Committee on National Finance 1/41-1463S, Senate Canada.

Degryse, H., Verboven, F., November 2000. Car price differentials in the European Union: An economic analysis. Report, Centre for Economic Policy Research.

Dudenhöffer, F., Neuberger, K., May 2011. Neuwagenkauf im Autohaus oder beim Internet-Vermittler: Wie zufrieden sind die Kunden?, CAR-Center Automotive Research, Universität Duisburg-Essen.

Engel, C., Rogers, J. H., 1996. How wide is the border? American Economic Review 86 (5), 1112-1125.

Engel, C., Rogers, J. H., 2001. Violating the law of one price: Should we make a federal case out of it? Journal of Money, Credit and Banking 33 (1), 1-15.

Engel, C., Rogers, J. H., Veronese, G., Midelfart, K. H., 2004. European product market integration after the Euro. Economic Policy 19 (39), 349-384.

European Commission, 1999. Directive 1999/44/EC of the European Parliament and of the Council of 25 May 1999 on certain aspects of the sale of consumer goods and associated guarantees. Official Journal of the European Communities 1999 (L 171), 12-16.

European Commission, 2002. Commission Regulation 1400/2002 of 31 July 2002 on the application of Article 81(3) of the Treaty to categories of vertical agreements and concerted practices in the motor vehicle sector. Official Journal of the European Communities 2002 (L 203), 30-41.

European Commission, 2004. Commission Directive 2003/127/EC of 23 December 2003 amending Council Directive 1999/37/EC on the registration documents for vehicles. Official Journal of the European Communities 2004 (L 10), 29-53.

European Commission, May 2008. The impact of Regulation 1400/2002: an effects-based analysis. Staff working document 4, Commission of the European Communities.

European Commission, May 2009. Commission evaluation report on the operation of Regulation (EC) 1400/2002 concerning motor vehicle distribution and servicing. Evaluation report, Commission of the European Communities.

European Commission, April 2013. Car price reports. Retrieved on April 4, 2014. http: / /ec.europa. eu/competition/sectors/motor_vehicles/prices/report.html.

European Commission DG-COMP, July 2002. Distribution and servicing of motor vehicles in the European Union: Explanatory brochure for Commission Regulation (EC) no 1400/2002 of 31 July 2002. Explanatory brochure, Commission of the European Communities - Directorate General for Competition.

European Commission DG-MOVE, November 2012. Supporting study to the impact assessments of the European Commissions internalisation strategy, to establish an inventory of measures for internalising external costs in all modes of transport: An inventory of measures for internalising external costs in transport. Final Report - Impact Assessments and Evaluations (ex-ante, intermediate and ex-post) in the field of the transport - Annex: MOVE/A3/350-2010, Commission of the European Communities - Directorate General for Mobility and Transport. 
Fang, H., Norman, P., 2006. To bundle or not to bundle. RAND Journal of Economics 37 (4), 946-963.

Fischer, C., 2012. Price convergence in the EMU? Evidence from micro data. European Economic Review 56 (4), 757-776.

Gaulier, G., Haller, S., 2000. The convergence of automobile prices in the European Union: An empirical analysis for the period 1993-1999. Working Paper 00-14, CEPII.

Gil-Pareja, S., 2003. Pricing to market behaviour in European car markets. European Economic Review 47 (6), 945-962.

Gil-Pareja, S., Sosvilla-Rivero, S., 2008. Price convergence in the European car market. Applied Economics 40 (2), 241-250.

Gil-Pareja, S., Sosvilla-Rivero, S., 2012. Convergence in car prices among European countries. Applied Economics 44 (25), 3247-3254.

Ginsburgh, V., Vanhamme, G., 1989. Price differences in the EC car market: Some further results. Annales D'Economie et de Statistique 1989 (15/16), 137-149.

Ginsburgh, V., Weber, S., 2002. Product lines and price discrimination in the European car market. Manchester School 70 (1), 101-114.

Goldberg, P. K., Verboven, F., 2001. The evolution of price dispersion in European car markets. Review of Economic Studies 68 (4), 811-848.

Goldberg, P. K., Verboven, F., 2004. Cross-country price dispersion in the Euro era: A case study of the European car market. Economic Policy 19 (40), 483-521.

Goldberg, P. K., Verboven, F., 2005. Market integration and convergence to the law of one price: Evidence from the European car market. Journal of International Economics 65 (1), 49-73.

Gopinath, G., Gourinchas, P.-O., Hsieh, C.-T., Li, N., 2011. International prices, costs, and markup differences. American Economic Review 101 (6), 2450-2486.

Gron, A., Swenson, D. L., 1996. Incomplete exchange rate pass-through and imperfect competition: The effect of local production. American Economic Review 86 (2), 71-76.

Haskel, J., Wolf, H., 2001. The law of one price: A case study. Scandinavian Journal of Economics 103 (4), 545-558.

Hassink, W. H., Schettkat, R., 2003. Price discrimination between EU regions. Tijdschrift voor Economische en Sociale Geografie 94 (2), 258-264.

Imbs, J., Mumtaz, H., Ravn, M. O., Rey, H., 2005. PPP strikes back: Aggregation and the real exchange rate. Quarterly Journal of Economics 120 (1), 1-43.

Kirman, A., Schueller, N., 1990. Price leadership and discrimination in the European car market. Journal of Industrial Economics 39 (1), 69-91.

Liao, C.-H., Tauman, Y., 2002. The role of bundling in price competition. International Journal of Industrial Organization 20 (3), 365-389.

Lutz, M., 2004. Pricing in segmented markets, arbitrage barriers and the law of one price: Evidence from the European car market. Review of International Economics 12 (3), 456-475.

Manelli, A. M., Vincent, D. R., 2006. Bundling as an optimal selling mechanism for a multiple-good monopolist. Journal of Economic Theory 127 (1), 1-35.

Mèjean, I., Schwellnus, C., 2009. Price convergence in the European Union: Within firms or composition of 
firms? Journal of International Economics 78 (1), 1-10.

Mertens, Y., 1990. Modeling price behavior in the European car market: 1970-1985, London School of Economics and Political Science.

Mertens, Y., Ginsburgh, V., 1985. Product differentiation and price discrimination in the European Community: The case of automobiles. Journal of Industrial Economics 34 (2), 151-166.

PricewaterhouseCoopers, 6 2004. International Fleet Guide. Fleet Europe Magazine and Eurofleet Consult.

PricewaterhouseCoopers, 9 2006. International Fleet Guide: Car taxation in 25 countries. Fleet Europe Magazine.

PricewaterhouseCoopers, 4 2008. International Fleet Guide: Update on car taxation in 16 countries. Fleet Europe Magazine.

PricewaterhouseCoopers, 4 2009. International Fleet Guide: Update on car taxation in CEE. Fleet Europe Magazine, Weiswampach (Luxemburg).

PricewaterhouseCoopers, 1 2010. International Fleet Guide: Update to car taxation. Fleet Europe Magazine, Weiswampach (Luxemburg).

PricewaterhouseCoopers, 5 2011. International Fleet Guide: Update to car taxation. Fleet Europe Magazine, Blegny (Belgium).

Spector, D., 2007. Bundling, tying, and collusion. International Journal of Industrial Organization 25 (3), $575-$ 581.

Strasser, G., 2013. Exchange rate pass-through and credit constraints. Journal of Monetary Economics 60 (1), $25-38$.

Vaubourg, A.-G., 2006. Differentiation and discrimination in a duopoly with two bundles. International Journal of Industrial Organization 24 (4), 753-762.

Verboven, F., 1996a. International price discrimination in the European car market. RAND Journal of Economics 27 (2), 240-268.

Verboven, F., 1996b. Quality-based price discrimination and tax incidence: Evidence from gasoline and diesel cars. RAND Journal of Economics 33 (2), 275-297. 
Figure 1: Cross-country Price Dispersion of Ford Focus

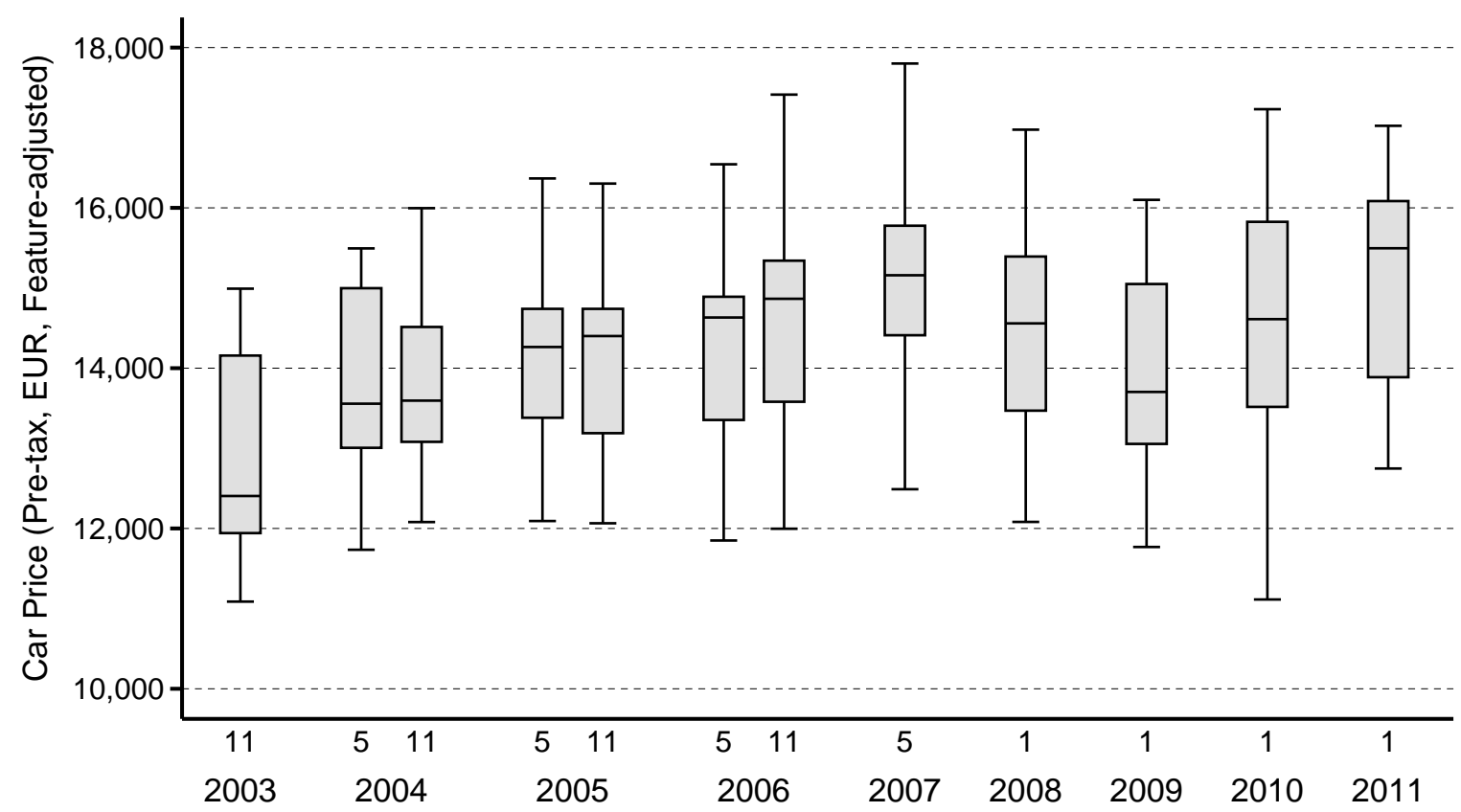

The graph shows the dispersion of feature-adjusted, pre-tax EUR prices of the Ford Focus with manual transmission, $P_{t}^{\text {Ford Focus M , c }}$, by year across the European countries where it is sold. Boxes represent the $25^{\text {th }}-75^{\text {th }}$ percentile range, with the horizontal line denoting the median. The "whiskers" represent the $10^{\text {th }}-90^{\text {th }}$ percentile range. 
Figure 2: Frequency Distribution of Model-Specific Real Exchange Rates

(a) vis-à-vis Germany

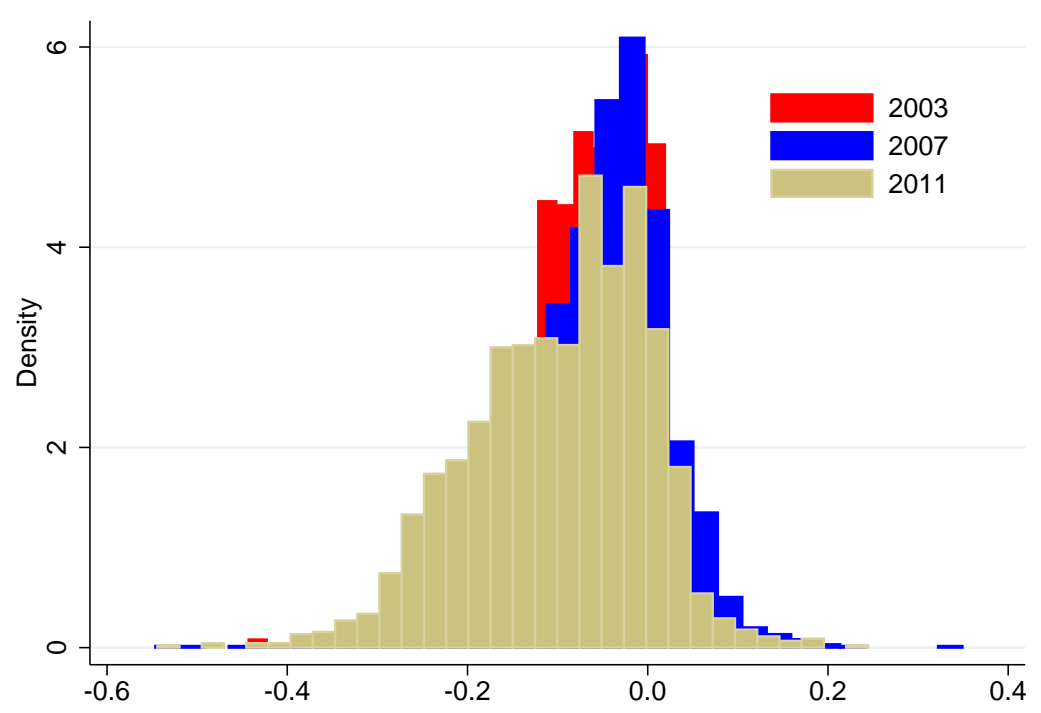

(b) vis-à-vis The Netherlands

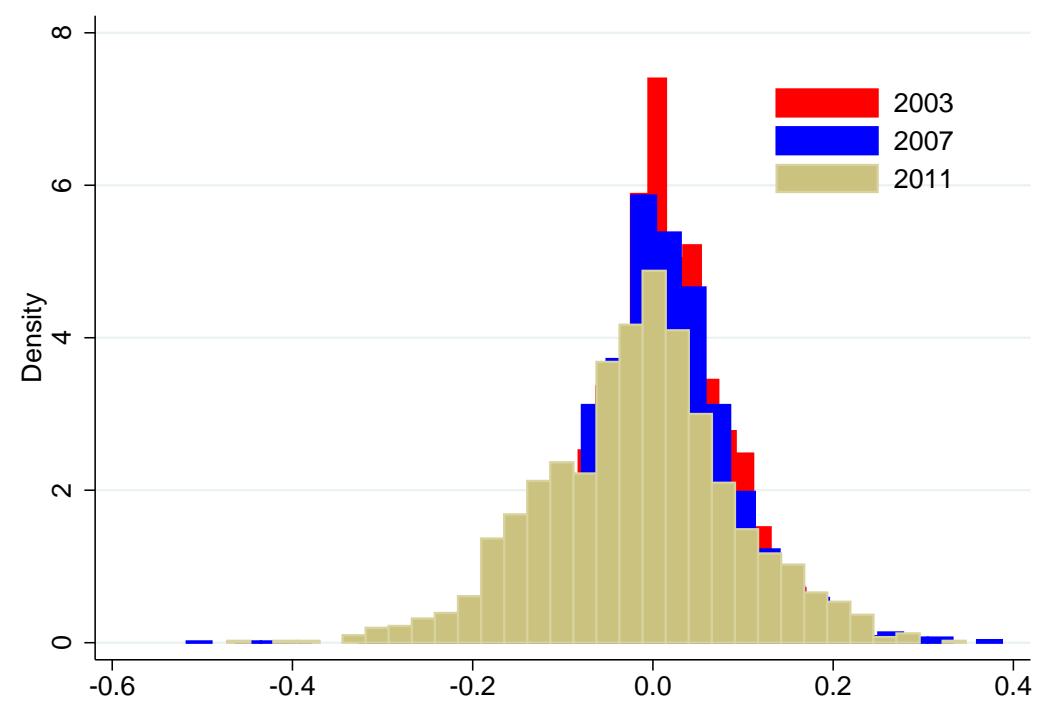

The histogram shows the frequency distribution of model-specific real exchange rates, $r_{2003 m 11}^{i, c}, r_{2007 m 5}^{i, c}$, and $r_{2011 m 1}^{i, c}$ relative to Germany in the upper panel and relative to the Netherlands in the lower panel. All models, excluding Seat. The real exchange rates are based on log, feature-adjusted, pre-tax prices. 
Figure 3: Log Price Dispersion

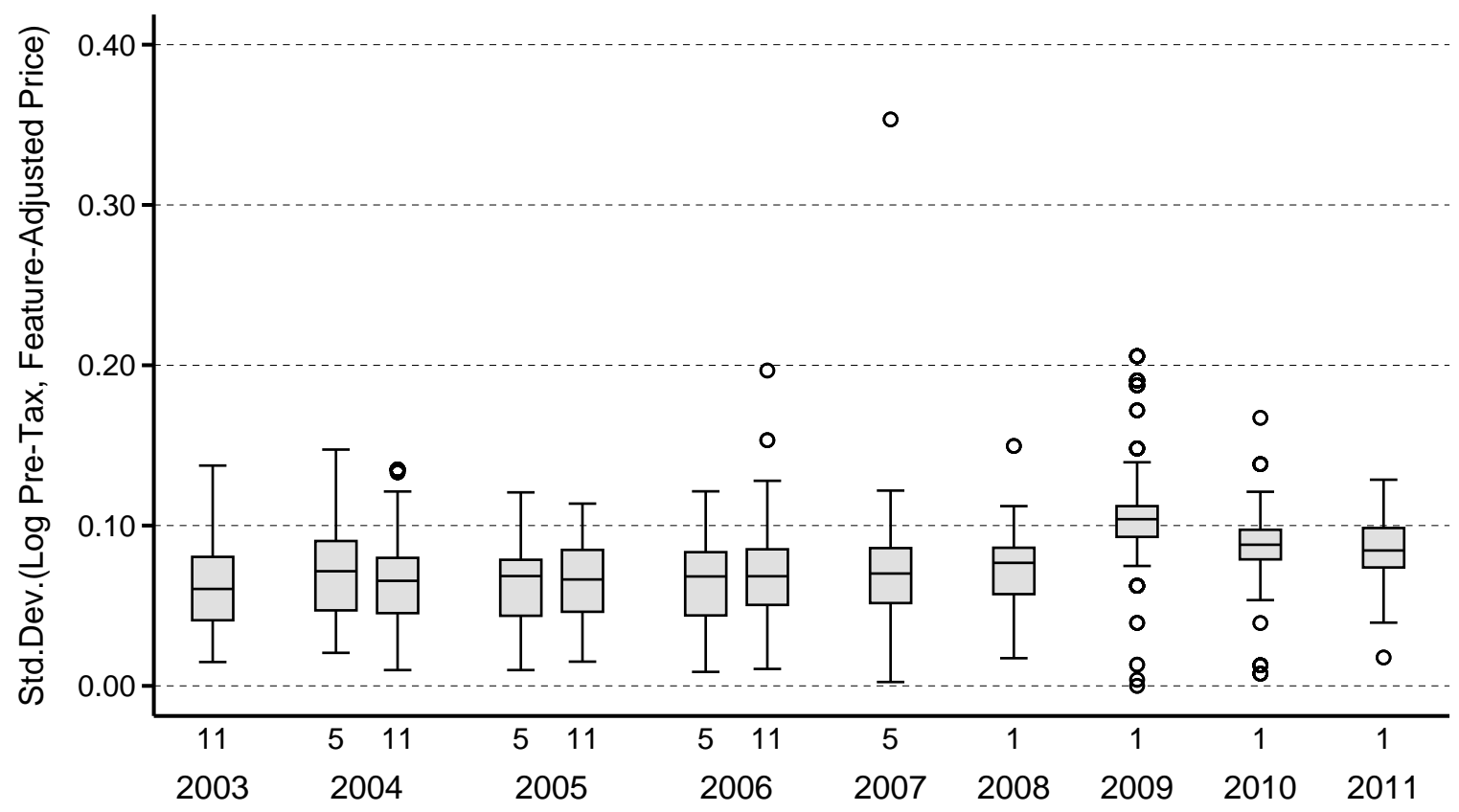

The graph shows the distribution across models of the model-specific cross-country dispersion of prices, $\Xi_{t}^{i}$. All models, excluding Seat. The underlying prices are in natural logs, feature-adjusted, and pre-tax. Boxes represent the $25^{\text {th }}-75^{\text {th }}$ percentile range, with the horizontal line denoting the median. The "whiskers" represent the $10^{\text {th }}-90^{\text {th }}$ percentile range. Circles represent outliers. 
Figure 4: Model-Specific Real Exchange Rates

(a) vis-à-vis Germany

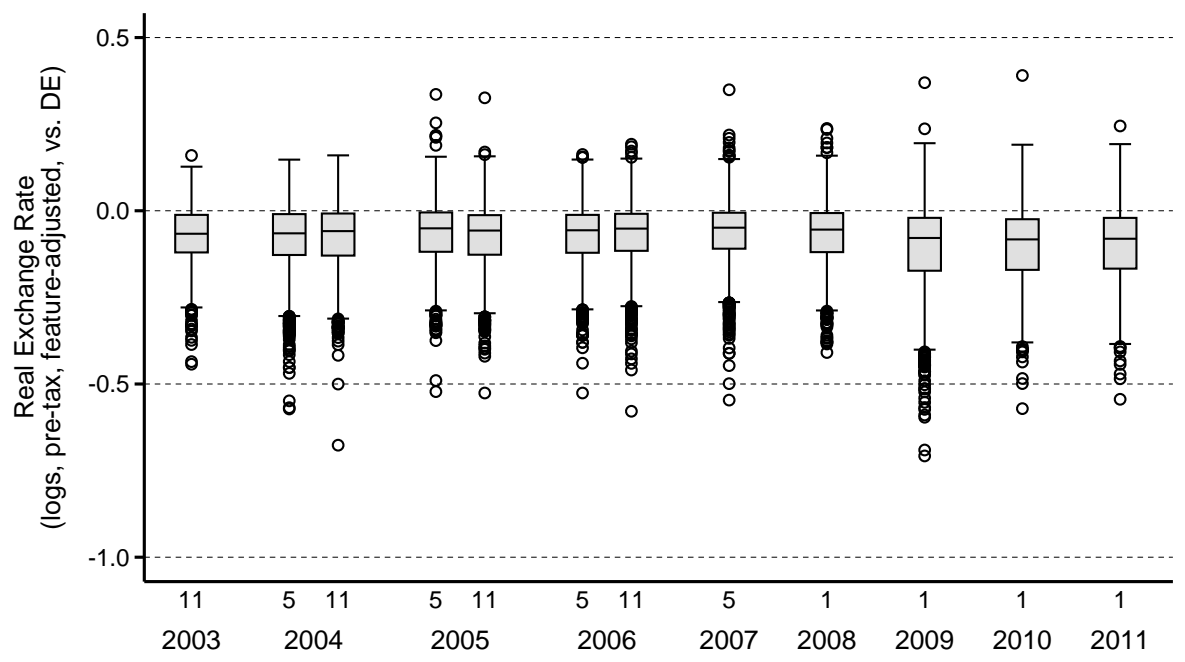

(b) vis-à-vis The Netherlands

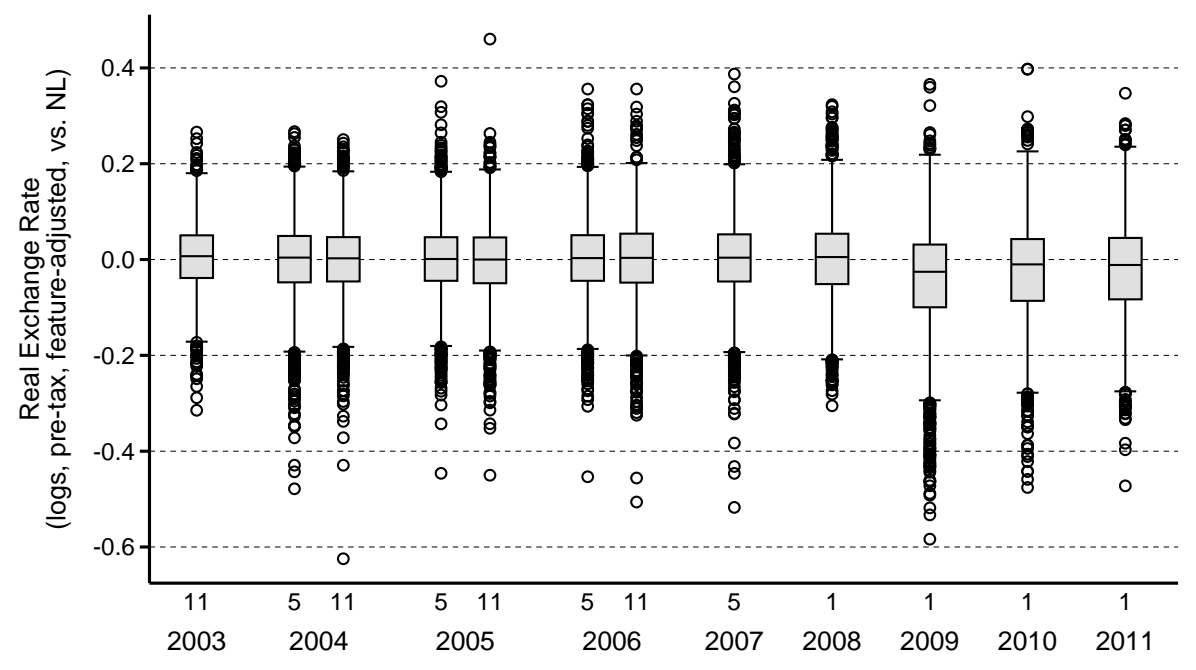

The graphs show the evolution of the dispersion of model-specific real exchange rates, $r_{t}^{i, c}$, relative to Germany in the upper panel and relative to the Netherlands in the lower panel. All models, excluding Seat. The real exchange rates are based on log, feature-adjusted, pre-tax prices. 
Figure 5: Segment Effects by Country

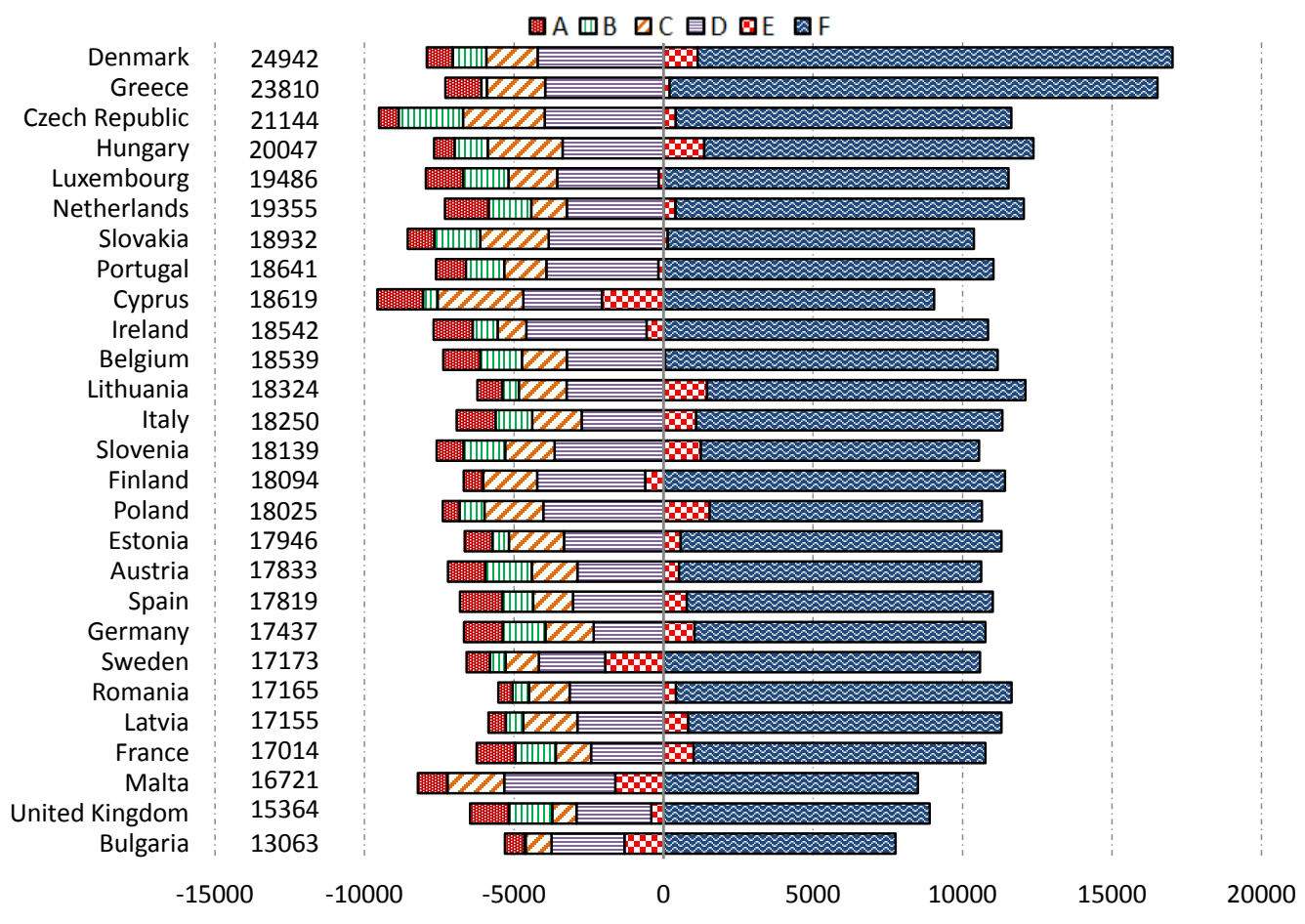

The graph shows the segment fixed effects relative to multipurpose cars (segment $\mathrm{G}$ ) by country, in euros, based on specification (3) in Table 3 . All models, excluding Seat. The underlying prices are in euros, feature-adjusted, and pre-tax. 


\section{Figure 6: Determinants of AC Price Difference}

(a) Latitude

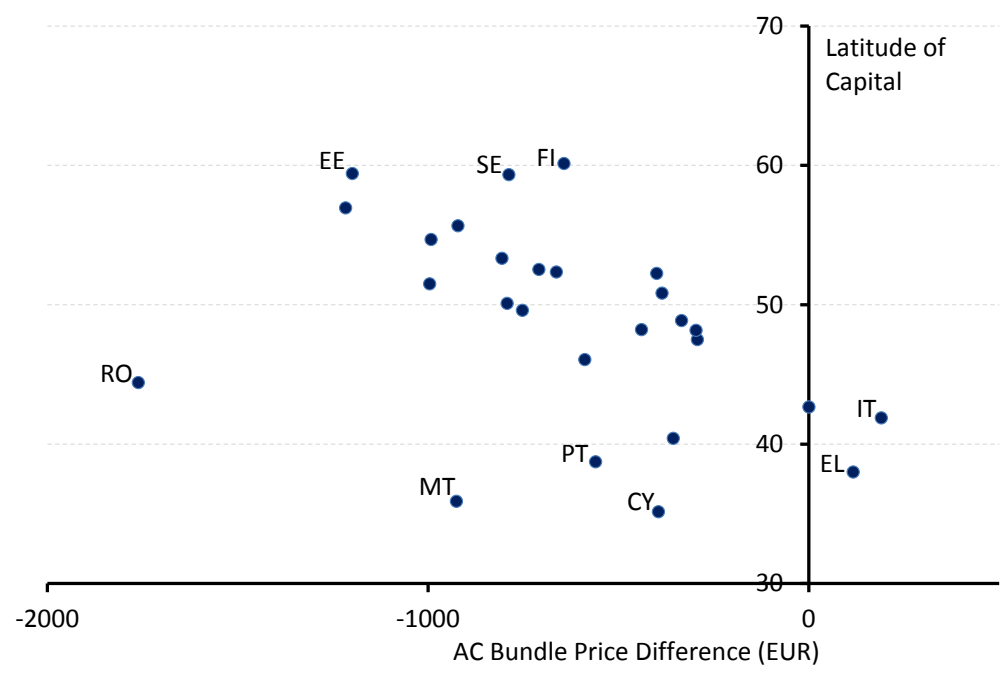

(b) Inequality

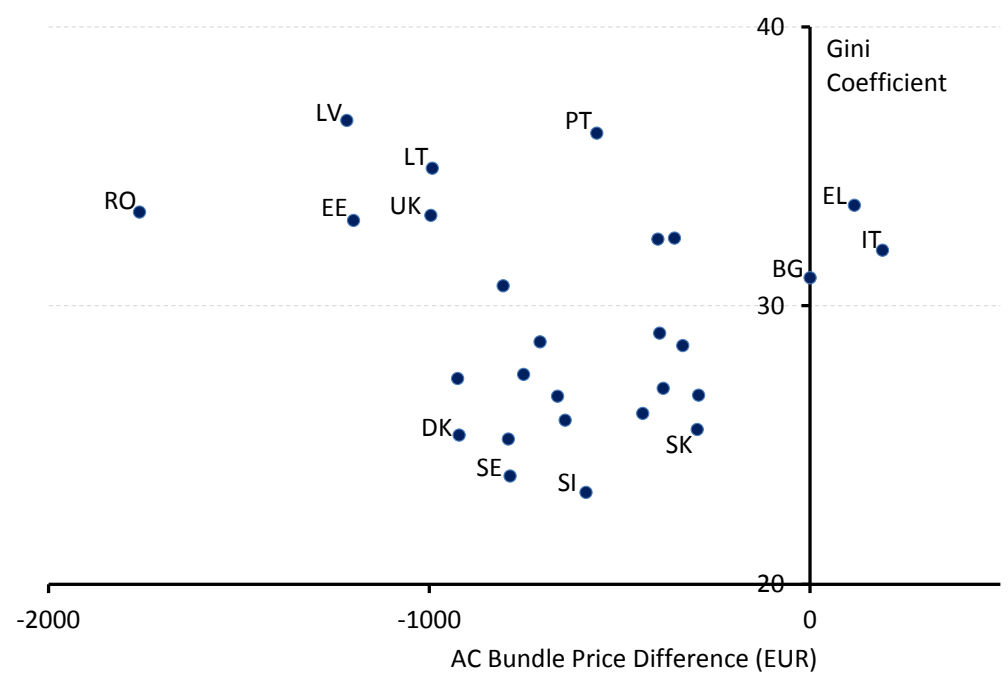

The graph shows the price discount (-) or surcharge (+) in EUR by country when AC is included as standard option $(\gamma-\bar{\gamma})$. Based on specification (4) in Table 3 Latitude is measured by the latitude of the country's capital. Gini coefficients are averages over annual values from 2003 to 2011 provided by Eurostat. All models, excluding Seat. The underlying prices are in euros, feature-adjusted, and pre-tax. 
Table 1: Time Trends in Price Dispersion

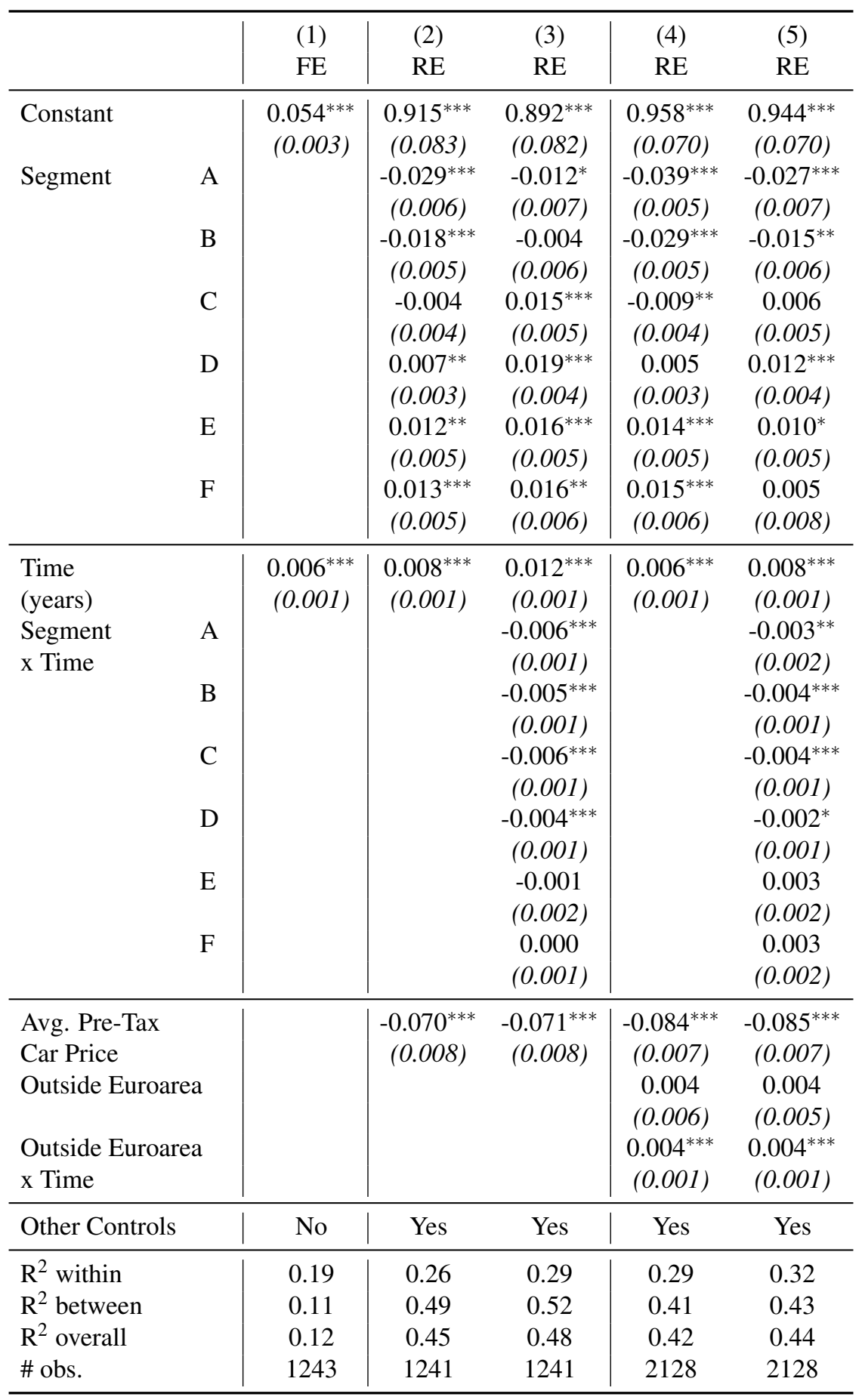

Dependent variable: Standard deviation across models of model price dispersion based on log, feature-adjusted, pre-tax EUR prices, $\Xi_{t}^{i}$. All models, excluding Seat. Model fixed effects in specification (1), and other model covariates in specifications (2) to (5) not reported. Random effects GLS estimation of Equation (1) in specifications (2) to (5). Bootstrap standard errors in parentheses. Asterisks indicate the level of significance, $(*)$ at the $10 \%,(* *)$ at the $5 \%$, and $(* * *)$ at the $1 \%$ level. Controls not listed in the table are engine power $(\mathrm{kW})$, engine size $(\mathrm{ccm})$, average and dispersion of effective tax due at registration $(\%)$, average and dispersion of VAT $(\%)$, average fuel consumption $(1 / 100 \mathrm{~km})$, diesel dummy, $\mathrm{HC}, \mathrm{NO}_{x}$, and particles emissions $(\mathrm{g} / \mathrm{km})$, and brand centrality. 
Table 2: Autoregressive Properties of the Real Exchange Rate

\begin{tabular}{|c|c|c|c|c|}
\hline Freq. (months) & (1) & $\begin{array}{c}2003-200 \\
6 \\
(2)\end{array}$ & (3) & $\begin{array}{c}2003-2011 \\
12 \\
(4)\end{array}$ \\
\hline $\begin{array}{l}\hat{r}_{t-1} \\
\hat{r}_{t-1}^{E U R}\end{array}$ & $\begin{array}{c}0.587^{* * *} \\
(0.068)\end{array}$ & $\begin{array}{c}0.424^{* * *} \\
(0.023)\end{array}$ & $\begin{array}{c}0.732^{* * *} \\
(0.164) \\
-0.331 \\
(0.247)\end{array}$ & $\begin{array}{c}0.148^{* * *} \\
(0.029)\end{array}$ \\
\hline $\begin{array}{l}\text { \# instruments } \\
\text { MA }(q) \text { of id. err. } \\
\text { \# observations } \\
\text { \# groups }\end{array}$ & $\begin{array}{c}28 \\
1 \\
9952 \\
3522\end{array}$ & $\begin{array}{c}35 \\
0 \\
9952 \\
3522\end{array}$ & $\begin{array}{c}28 \\
1 \\
9952 \\
3522\end{array}$ & $\begin{array}{c}23 \\
0 \\
6352 \\
3684\end{array}$ \\
\hline
\end{tabular}

Dependent variable: Real exchange rates $\hat{r}^{i, c}$ demeaned by model and country over the respective subsample. Arellano-Bover system estimation of Equation (2). All models, excluding Seat. Survey fixed effects are not reported. Arellano-Bond robust standard errors adjusted for clustering on model-country in parentheses. Asterisks indicate the level of significance, $(*)$ at the $10 \%,(* *)$ at the $5 \%$, and $(* * *)$ at the $1 \%$ level. 
Table 3: Price Regression

\begin{tabular}{|c|c|c|c|c|}
\hline & $\begin{array}{l}(1) \\
\text { FE }\end{array}$ & $\begin{array}{l}\text { (2) } \\
\mathrm{RE}\end{array}$ & $\begin{array}{c}(3) \\
R E+T^{3}\end{array}$ & RE $+A C \times$ Country \\
\hline $\begin{array}{l}\text { Engine Capacity } \\
(\mathrm{ccm})\end{array}$ & $\begin{array}{c}3.61^{* * *} \\
(0.42)\end{array}$ & $\begin{array}{c}5.85^{* * *} \\
(0.46)\end{array}$ & $\begin{array}{l}5.75^{* * *} \\
(0.46)\end{array}$ & $\begin{array}{l}5.85^{* * *} \\
(0.45)\end{array}$ \\
\hline Engine Power & $18.63^{* * *}$ & $47.97^{* * *}$ & $47.44^{* * *}$ & $48.03^{* * *}$ \\
\hline$(\mathrm{kW})$ & $(3.89)$ & $(3.59)$ & $(3.46)$ & $(3.51)$ \\
\hline $\mathrm{NO}_{x}$ & $-2.06^{* * *}$ & $-2.37^{* * * *}$ & $-2.28^{* *}$ & $-2.36^{* * *}$ \\
\hline$(\mathrm{mg} / \mathrm{km})$ & $(0.41)$ & $(0.44)$ & $(0.41)$ & $(0.43)$ \\
\hline & $-13.39^{* * *}$ & $-8.50^{* * *}$ & $-8.58^{* * *}$ & $-8.48^{* * *}$ \\
\hline$(\mathrm{mg} / \mathrm{km})$ & $(1.32)$ & (1.58) & (1.61) & $(1.66)$ \\
\hline Particles & $-15.44^{* * *}$ & $-25.10^{* * *}$ & $-23.92^{* * *}$ & $-25.05^{* * *}$ \\
\hline$(\mathrm{mg} / \mathrm{km})$ & $(2.85)$ & (3.13) & (3.07) & (3.14) \\
\hline Warranty & 12.47 & -53.15 & -53.15 & -53.19 \\
\hline (years) & $(43.71)$ & (45.43) & $(41.89)$ & $(43.69)$ \\
\hline AGB & & $1143.74^{* * *}$ & $1184.82^{* * *}$ & $1139.64^{* * *}$ \\
\hline (1=yes) & & (93.35) & (93.27) & (97.43) \\
\hline $\begin{array}{l}\mathrm{AC} \\
(1=\operatorname{standard})\end{array}$ & $\begin{array}{l}-790.25^{* * *} \\
(5988)\end{array}$ & $\begin{array}{l}-607.24^{* * *} \\
(5842)\end{array}$ & $-580.09^{* * *}$ & Interacted with \\
\hline ABS & $-689.55^{* * *}$ & $-354.99^{* * *}$ & $-364.10^{* *}$ & $-332.52^{* *}$ \\
\hline (1=standard $)$ & (137.74) & $(141.18)$ & (148.67) & $(136.18)$ \\
\hline Airbag & $-972.27^{* * *}$ & $-1190.23^{* * *}$ & $-1170.31^{* * *}$ & $-1176.90^{* * *}$ \\
\hline (1=standard) & (151.68) & (150.39) & (159.19) & (145.38) \\
\hline Fuel Type & -1448.09 & $13477.88^{* * *}$ & $13409.27^{* * *}$ & $13493.85^{* * *}$ \\
\hline & (1000.7J) & (1070.21) & $(1000.11)$ & $(1004.41)$ \\
\hline Fuel Consumption & $87.25^{* * *}$ & $-70.18^{* *}$ & $-71.73^{* * *}$ & $-72.10^{* * *}$ \\
\hline (petrol, $1 / 1000 \mathrm{~km})$ & $(31.84)$ & $(27.91)$ & $(27.83)$ & $(25.80)$ \\
\hline Fuel Consumption & $180.24^{* * *}$ & $-588.09^{* * *}$ & $-580.82^{* * *}$ & $-590.96^{* * *}$ \\
\hline (diesel, 1/1000km) & $(63.12)$ & $(66.05)$ & $(63.24)$ & (61.97) \\
\hline Fuel Cons. Sq. & $-0.76^{* * *}$ & $0.30^{*}$ & $0.29^{*}$ & $0.31^{*}$ \\
\hline (petrol, 1/1000km) & $(0.20)$ & $(0.18)$ & $(0.18)$ & $(0.16)$ \\
\hline Fuel Cons. Sq. & $-1.51^{* * *}$ & $5.42^{* * *}$ & $5.33^{* * *}$ & $5.45^{* * *}$ \\
\hline (diesel, 1/1000km) & $(0.55)$ & $(0.55)$ & $(0.52)$ & $(0.51)$ \\
\hline Diesel-Petrol Tax & $97.26^{* * *}$ & $94.26^{* * *}$ & $64.21^{* * *}$ & $94.77^{* * *}$ \\
\hline (petrol, ct/l) & $(11.45)$ & (11.84) & (11.75) & (11.59) \\
\hline Diesel-Petrol Tax & $73.00^{* * *}$ & $68.89^{* * *}$ & $55.16^{* * *}$ & $70.97^{* * *}$ \\
\hline (diesel, ct/l) & $(12.83)$ & (11.68) & $(12.41)$ & $(12.27)$ \\
\hline Population & -98.17 & -102.57 & 15.44 & $-119.99^{*}$ \\
\hline (millions) & (63.03) & $(63.73)$ & $(130.42)$ & $(62.52)$ \\
\hline GDP p.c. & $42.24^{* * *}$ & $39.89^{* * *}$ & $-27.45^{*}$ & $40.24^{* * *}$ \\
\hline (1000 EUR @ PPP) & (14.88) & $(15.25)$ & (15.94) & $(15.48)$ \\
\hline Distance & 50.63 & $175.46^{* *}$ & $135.02^{*}$ & $165.66^{* *}$ \\
\hline$(1000 \mathrm{~km})$ & (97.94) & $(72.84)$ & $(74.26)$ & (69.67) \\
\hline VAT & $131.07^{* * *}$ & $122.00^{* * *}$ & $138.12^{* * *}$ & $128.43^{* * *}$ \\
\hline & $(20.50)$ & (21.54) & (27.92) & (21.99) \\
\hline Petrol Tax & $109.04^{* * *}$ & $104.62^{* * *}$ & $132.63^{* * *}$ & $104.87^{* * *}$ \\
\hline$(\mathrm{ct} / \mathrm{l})$ & (9.01) & $(9.24)$ & (10.05) & $(9.15)$ \\
\hline Eff. Registration Tax & -11.56 & -6.95 & -5.71 & -6.92 \\
\hline$(\%)$ & (7.69) & $(6.25)$ & $(6.94)$ & $(6.28)$ \\
\hline Time Effects & Yes & Yes & Yes & Yes \\
\hline Segment Effects & No & Yes & Yes & Yes \\
\hline Country, Home, Brand Effects & No & Yes & Yes & Yes \\
\hline Country Effects $\times \mathrm{T}^{3}$ & No & No & Yes & No \\
\hline $\mathrm{R}^{2}$ within & 0.42 & 0.37 & 0.42 & 0.37 \\
\hline $\mathrm{R}^{2}$ overall & 0.98 & 0.94 & 0.94 & 0.94 \\
\hline
\end{tabular}

Dependent variable: Feature-adjusted, pre-tax EUR prices, $P_{t}^{i, c}$. Estimation equation 3 . All models, excluding Seat, 23028 observations in 4352 groups. Constant, fixed effects, and time trends are not reported. Bootstrap standard errors in parentheses. Asterisks indicate the level of significance, $(*)$ at the $10 \%,(* *)$ at the $5 \%$, and $(* * *)$ at the $1 \%$ level. 
Table 4: Car Segment Effects

\begin{tabular}{lc|c|c}
\hline & & $(2)$ & $(3)$ \\
Segment & & $\mathrm{RE}$ & $\mathrm{RE}+\mathrm{T}^{3}$ \\
\hline Mini & $\mathrm{A}$ & $-7659^{* * *}$ & $-7836^{* * *}$ \\
& & $(308)$ & $(302)$ \\
Small & $\mathrm{B}$ & $-6340^{* * *}$ & $-6509^{* * *}$ \\
& & $(275)$ & $(268)$ \\
Medium & $\mathrm{C}$ & $-5169^{* * *}$ & $-5297^{* * *}$ \\
& & $(250)$ & $(244)$ \\
Large & $\mathrm{D}$ & $-3536^{* * *}$ & $-3622^{* * *}$ \\
& & $(211)$ & $(209)$ \\
Executive & $\mathrm{E}$ & 259 & 182 \\
& & $(260)$ & $(270)$ \\
Luxury & $\mathrm{F}$ & $10932^{* * *}$ & $11054^{* * *}$ \\
& & $(622)$ & $(665)$ \\
\hline
\end{tabular}

Segment effects from regression specifications (2) and (3) in Table 3 relative to multipurpose cars (segment G). See notes to Table 3 . 
Table 5: Brand Effects

\begin{tabular}{lc}
\hline Mercedes-Benz & $6774^{* * *}$ \\
BMW & $5958^{* * *}$ \\
Saab & $5798^{* * *}$ \\
\hline Audi & $2941^{* * *}$ \\
Mini & $2709^{* * *}$ \\
Subaru & $2608^{* * *}$ \\
Alfa Romeo & $2448^{* * *}$ \\
\hline Citroen & $1020^{* * *}$ \\
Renault & $618^{* * *}$ \\
Peugeot & 274 \\
Volkswagen & 182 \\
Toyota & 0 \\
\hline Honda & $-527^{* * *}$ \\
Fiat & $-542^{* *}$ \\
Opel & $-574^{* * *}$ \\
Kia & $-602^{* *}$ \\
\hline Ford & $-745^{* * *}$ \\
Mitsubishi & $-749^{* *}$ \\
Nissan & $-786^{* * *}$ \\
Mazda & $-969^{* * *}$ \\
\hline Hyundai & $-1087^{* * *}$ \\
MG Rover & $-1289^{* * *}$ \\
Land Rover & $-1365^{* *}$ \\
Volvo & $-1529^{* * *}$ \\
\hline Skoda & $-1968^{* * *}$ \\
Daihatsu & $-1992^{* * *}$ \\
Suzuki & $-3621^{* * *}$ \\
\hline
\end{tabular}

Brand effects from regression specification (3) relative to Toyota. See notes to Table 3 
Table 6: AC Bundling Discount by Country

\begin{tabular}{l|l}
\hline & $\begin{array}{l}\text { AC } \\
(1=\text { standard })\end{array}$ \\
\hline Romania & $-1761^{* * *}$ \\
Latvia & $-1217^{* * *}$ \\
Estonia & $-1199^{* * *}$ \\
\hline United Kgd. & $-996^{* * *}$ \\
Lithuania & $-992^{* * *}$ \\
Malta & $-926^{* * *}$ \\
Denmark & $-922^{* * *}$ \\
Ireland & $-806^{* * *}$ \\
Czech Rep. & $-792^{* * *}$ \\
Sweden & $-788^{* * *}$ \\
Luxembourg & $-752^{* * *}$ \\
Germany & $-709^{* * *}$ \\
Netherlands & $-663^{* * *}$ \\
Finland & $-643^{* * *}$ \\
Slovenia & $-588^{* * *}$ \\
Portugal & $-560^{* *}$ \\
\hline Austria & $-440^{* *}$ \\
Poland & $-400^{*}$ \\
Cyprus & -395 \\
Belgium & $-386^{*}$ \\
Spain & -356 \\
France & -334 \\
Slovakia & -296 \\
Hungary & $-293^{*}$ \\
\hline Bulgaria & 0 \\
Greece & 116 \\
Italy & 190 \\
\hline Crsandard & 05 \\
\hline
\end{tabular}

Country-specific coefficients on the "AC standard" indicator from regression specification (4) of Table 3, sorted by value. See notes to Table 3 
Table 7: Correlation of Customer Segment Specific Pricing

\begin{tabular}{l|ccc}
\hline & $\underline{\gamma}-\bar{\gamma}$ & $\bar{\gamma}$ & $\underline{\gamma}$ \\
\hline Latitude & -0.43 & 0.05 & -0.13 \\
Gini Coefficent & -0.15 & -0.26 & -0.31 \\
\hline
\end{tabular}


Table 8: AC Pricing by Country and Customer Segment

\begin{tabular}{|c|c|c|}
\hline $\begin{array}{l}\text { Germany } \\
\text { Netherlands } \\
\text { Belgium }\end{array}$ & $\begin{array}{l}\bar{\gamma} \\
\bar{\gamma} \\
\bar{\gamma}\end{array}$ & $\begin{array}{l}8943 \\
8780 \\
8758\end{array}$ \\
\hline $\begin{array}{l}\text { Belgium } \\
\text { Portugal } \\
\text { Luxembourg } \\
\text { Germany } \\
\text { Spain } \\
\text { Netherlands }\end{array}$ & $\begin{array}{l}\frac{\gamma}{\bar{\gamma}} \\
\bar{\gamma} \\
\gamma \\
\overline{\bar{\gamma}} \\
\underline{\gamma}\end{array}$ & $\begin{array}{l}8372 \\
\mathbf{8 2 9 8} \\
\mathbf{8 2 8 6} \\
8234 \\
\mathbf{8 1 9 6} \\
8117\end{array}$ \\
\hline $\begin{array}{l}\text { Spain } \\
\text { Czech Rep. } \\
\text { Austria } \\
\text { Portugal } \\
\text { Romania } \\
\text { Denmark } \\
\text { Luxembourg }\end{array}$ & $\begin{array}{l}\frac{\gamma}{\bar{\gamma}} \\
\bar{\gamma} \\
\underline{\bar{\gamma}} \\
\bar{\gamma} \\
\underline{\gamma}\end{array}$ & $\begin{array}{l}7840 \\
\mathbf{7 8 1 1} \\
\mathbf{7 7 9 4} \\
7738 \\
\mathbf{7 6 6 1} \\
\mathbf{7 5 6 0} \\
7534\end{array}$ \\
\hline $\begin{array}{l}\text { Ireland } \\
\text { Austria } \\
\text { Italy } \\
\text { Finland } \\
\text { Italy } \\
\text { Czech Rep. }\end{array}$ & $\begin{array}{l}\bar{\gamma} \\
\underline{\gamma} \\
\bar{\gamma} \\
\bar{\gamma} \\
\underline{\gamma}\end{array}$ & $\begin{array}{l}\mathbf{7 3 7 5} \\
7354 \\
7281 \\
\mathbf{7 2 4 0} \\
\mathbf{7 0 9 1} \\
7018 \\
\end{array}$ \\
\hline $\begin{array}{l}\text { Slovakia } \\
\text { Malta } \\
\text { France } \\
\text { Sweden } \\
\text { Slovakia } \\
\text { Denmark } \\
\text { Slovenia } \\
\text { Finland } \\
\text { Ireland } \\
\text { Poland }\end{array}$ & $\begin{array}{l}\bar{\gamma} \\
\bar{\gamma} \\
\bar{\gamma} \\
\bar{\gamma} \\
\frac{\gamma}{\gamma} \\
\bar{\gamma} \\
\frac{\gamma}{\gamma} \\
\bar{\gamma}\end{array}$ & $\begin{array}{l}\mathbf{6 9 9 9} \\
\mathbf{6 9 5 6} \\
\mathbf{6 7 6 9} \\
\mathbf{6 7 6 4} \\
6702 \\
6639 \\
6624 \\
6597 \\
6569 \\
\mathbf{6 5 0 9}\end{array}$ \\
\hline $\begin{array}{l}\text { France } \\
\text { Latvia } \\
\text { Poland } \\
\text { Lithuania } \\
\text { Slovenia } \\
\text { Greece } \\
\text { Malta }\end{array}$ & $\begin{array}{l}\frac{\gamma}{\gamma} \\
\gamma \\
\overline{\bar{\gamma}} \\
\frac{\gamma}{\gamma} \\
\underline{\gamma}\end{array}$ & $\begin{array}{l}6435 \\
\mathbf{6 3 4 3} \\
6110 \\
\mathbf{6 0 8 1} \\
6035 \\
6030 \\
6030 \\
\end{array}$ \\
\hline $\begin{array}{l}\text { Hungary } \\
\text { Sweden } \\
\text { Estonia } \\
\text { Greece } \\
\text { Romania } \\
\text { Cyprus } \\
\text { United Kgd. } \\
\text { Hungary } \\
\text { Bulgaria } \\
\text { Bulgaria }\end{array}$ & $\begin{array}{l}\bar{\gamma} \\
\bar{\gamma} \\
\bar{\gamma} \\
\frac{\gamma}{\bar{\gamma}} \\
\bar{\gamma} \\
\frac{\gamma}{\gamma} \\
\overline{\bar{\gamma}}\end{array}$ & $\begin{array}{l}\mathbf{5 9 8 4} \\
5976 \\
\mathbf{5 9 2 5} \\
\mathbf{5 9 1 4} \\
5900 \\
\mathbf{5 8 9 4} \\
\mathbf{5 7 1 1} \\
5691 \\
5674 \\
\mathbf{5 6 7 4}\end{array}$ \\
\hline $\begin{array}{l}\text { Cyprus } \\
\text { Latvia } \\
\text { Lithuania }\end{array}$ & $\frac{\gamma}{\gamma}$ & $\begin{array}{l}5499 \\
5127 \\
5089\end{array}$ \\
\hline $\begin{array}{l}\text { Estonia } \\
\text { United Kgd. }\end{array}$ & $\frac{\gamma}{\gamma}$ & $\begin{array}{l}4726 \\
4715\end{array}$ \\
\hline
\end{tabular}

Country-specific valuation of AC by customer segment in EUR. Calculated from country means and the coefficients of regression specification (4) of Table 3 and sorted by value. Upper segment in bold. 
Table 9: Real Exchange Rate Regression

\begin{tabular}{|c|c|c|c|c|c|}
\hline & $\begin{array}{l}\text { (1) } \\
\mathrm{FE}\end{array}$ & $\begin{array}{l}(2) \\
\mathrm{RE}\end{array}$ & $\begin{array}{l}\text { (3) } \\
\mathrm{RE}\end{array}$ & $\begin{array}{l}(4) \\
\mathrm{RE}\end{array}$ & $\begin{array}{l}(5) \\
\mathrm{RE}\end{array}$ \\
\hline $\begin{array}{l}\text { AC } \\
\text { (Excluded in Both) } \\
\text { AC } \\
\text { (Included in NL Only) } \\
\text { AC } \\
\text { (Included in Other Country Only) } \\
\text { ABS } \\
\text { (Excluded in Both) } \\
\text { ABS } \\
\text { (Included in NL Only) } \\
\text { ABS } \\
\text { (Included in Other Country Only) } \\
\text { Airbag } \\
\text { (Excluded in Both) } \\
\text { Airbag } \\
\text { (Included in NL Only) }\end{array}$ & $\begin{array}{c}-0.64 \\
(0.78) \\
7.50^{* * *} \\
(1.20) \\
-8.03^{* * *} \\
(1.72) \\
-0.05 \\
(0.72) \\
4.30^{* *} \\
(1.96) \\
-4.68^{* * *} \\
(0.76) \\
-7.38^{* * *} \\
(0.69) \\
0.61 \\
(1.02)\end{array}$ & $\begin{array}{l}-0.26 \\
(0.67) \\
7.81^{* * *} \\
(1.08) \\
-7.93^{* * *} \\
(1.53) \\
-0.89 \\
(1.22) \\
3.79^{* *} \\
(1.74) \\
-3.85^{* * *} \\
(1.40) \\
-7.59^{* * *} \\
(0.63) \\
0.39 \\
(0.94)\end{array}$ & $\begin{array}{l}-0.11 \\
(0.67) \\
7.79^{* * *} \\
(1.06) \\
-7.84^{* * *} \\
(1.51) \\
-0.94 \\
(1.16) \\
3.94^{* *} \\
(1.75) \\
-3.89^{* * *} \\
(1.37) \\
-7.67^{* * *} \\
(0.64) \\
0.30 \\
(0.96)\end{array}$ & $\begin{array}{c}0.01 \\
(0.67) \\
8.42^{* * *} \\
(0.98) \\
-7.65^{* * *} \\
(1.52) \\
-0.89 \\
(1.15) \\
3.89^{* *} \\
(1.79) \\
-3.74^{* * *} \\
(1.35) \\
-7.84^{* * *} \\
(0.65) \\
0.21 \\
(0.96)\end{array}$ & $\begin{array}{l}\text { Interacted } \\
\text { with } \\
\text { Country } \\
\text { Dummies } \\
-7.96^{* * *} \\
(1.51) \\
-0.78 \\
(1.15) \\
3.82^{* *} \\
(1.63) \\
-3.63^{* * *} \\
(1.45) \\
-7.59^{* * *} \\
(0.67) \\
0.06 \\
(0.96)\end{array}$ \\
\hline $\begin{array}{l}\text { Warranty Diff. } \\
\text { (years) } \\
\text { Brand Centrality Diff. }\end{array}$ & $\begin{array}{c}0.25 \\
(0.25)\end{array}$ & $\begin{array}{c}0.16 \\
(0.25)\end{array}$ & $\begin{array}{l}0.13 \\
(0.24) \\
-4.13^{*} \\
(2.28)\end{array}$ & $\begin{array}{c}0.12 \\
(0.24) \\
-4.24^{*} \\
(2.29)\end{array}$ & $\begin{array}{l}0.13 \\
(0.23) \\
-3.29 \\
(2.25)\end{array}$ \\
\hline $\begin{array}{l}\text { Population Diff. } \\
\text { (1000s) } \\
\text { GDP p.c. Diff. } \\
\text { (1000 EUR @ PPP) } \\
\text { Distance Diff. } \\
\text { (1000 km) } \\
\text { VAT Diff. } \\
(\%) \\
\text { Petrol Tax Diff. } \\
\text { (ct/l) } \\
\text { Diesel-Petrol Tax Diff. } \\
\text { (Petrol, ct/l) } \\
\text { Diesel-Petrol Tax Diff. } \\
\text { (Diesel, ct/l) } \\
\text { Eff. Registration Tax Diff. } \\
\text { (\%) } \\
\text { Other Country in Eurozone }\end{array}$ & $\begin{array}{c}-0.37^{* *} \\
(0.18) \\
0.20^{* * *} \\
(0.05) \\
-0.26 \\
(1.05) \\
0.41^{* * *} \\
(0.10) \\
0.57^{* * *} \\
(0.03) \\
0.50^{* * *} \\
(0.03) \\
0.42^{* * *} \\
(0.04) \\
-0.01 \\
(0.03) \\
-1.00^{* *} \\
(0.48)\end{array}$ & $\begin{array}{c}-0.39^{* *} \\
(0.17) \\
0.21^{* * *} \\
(0.04) \\
-0.67^{*} \\
(0.35) \\
0.37^{* * *} \\
(0.09) \\
0.56^{* * *} \\
(0.03) \\
0.48^{* * *} \\
(0.03) \\
0.43^{* * *} \\
(0.04) \\
0.02 \\
(0.02) \\
-0.94^{* *} \\
(0.44)\end{array}$ & $\begin{array}{c}-0.40^{* *} \\
(0.17) \\
0.22^{* * *} \\
(0.04) \\
-0.75^{* *} \\
(0.34) \\
0.38^{* * *} \\
(0.09) \\
0.57^{* * *} \\
(0.03) \\
0.49^{* * *} \\
(0.03) \\
0.44^{* * *} \\
(0.04) \\
0.01 \\
(0.02) \\
-0.97^{* *} \\
(0.44)\end{array}$ & $\begin{array}{c}-0.45^{* * *} \\
(0.16) \\
0.22^{* * *} \\
(0.04) \\
-0.77^{* *} \\
(0.36) \\
0.10^{* * *} \\
(0.10) \\
0.57^{* * *} \\
(0.03) \\
0.49^{* * *} \\
(0.03) \\
0.44^{* * *} \\
(0.04) \\
0.01 \\
(0.02) \\
-0.96^{*} \\
(0.43)\end{array}$ & $\begin{array}{c}-0.52^{* *} \\
(0.17) \\
0.21^{* * *} \\
(0.04) \\
-0.76^{* *} \\
(0.33) \\
0.40^{* * *} \\
(0.09) \\
0.57^{* * *} \\
(0.03) \\
0.49^{* * *} \\
(0.03) \\
0.45^{* * *} \\
(0.04) \\
0.01 \\
(0.02) \\
-1.08^{* *} \\
(0.44)\end{array}$ \\
\hline $\begin{array}{l}\text { Czech Republic } \\
\text { (Home Effect) } \\
\text { France } \\
\text { (Home Effect) } \\
\text { Germany } \\
\text { (Home Effect) } \\
\text { Italy } \\
\text { (Home Effect) } \\
\text { Sweden } \\
\text { (Home Effect) } \\
\text { United Kingdom } \\
\text { (Home Effect) }\end{array}$ & & & $\begin{array}{c}4.85^{* * *} \\
(1.56) \\
5.87^{* * *} \\
(0.70) \\
-3.02^{* * *} \\
(1.03) \\
1.29 \\
(1.47) \\
-8.48^{* * *} \\
(1.59) \\
-2.00 \\
(3.42)\end{array}$ & $\begin{array}{c}4.90^{* * *} \\
(1.55) \\
5.88^{* * *} \\
(0.69) \\
-3.18^{* * *} \\
(1.04) \\
1.22 \\
(1.44) \\
-8.38^{* * *} \\
(1.57) \\
-1.94 \\
(3.25)\end{array}$ & $\begin{array}{c}5.32^{* * *} \\
(1.54) \\
5.97^{* * *} \\
(0.69) \\
-2.96^{* * *} \\
(1.02) \\
1.49 \\
(1.30) \\
-8.05^{* * *} \\
(1.65) \\
-3.44 \\
(3.58)\end{array}$ \\
\hline $\begin{array}{l}\text { Technical Spec. Controls } \\
\text { Segment Controls } \\
\text { Dealer Services Controls } \\
\text { Country Characteristic-Car Feature Interactions }\end{array}$ & $\begin{array}{l}\text { Yes } \\
\text { No } \\
\text { No } \\
\text { No }\end{array}$ & $\begin{array}{l}\text { Yes } \\
\text { Yes } \\
\text { No } \\
\text { No }\end{array}$ & $\begin{array}{l}\text { Yes } \\
\text { Yes } \\
\text { Yes } \\
\text { No }\end{array}$ & $\begin{array}{l}\text { Yes } \\
\text { Yes } \\
\text { Yes } \\
\text { Yes }\end{array}$ & $\begin{array}{l}\text { Yes } \\
\text { Yes } \\
\text { Yes } \\
\text { No }\end{array}$ \\
\hline $\begin{array}{l}R^{2} \text { within } \\
R^{2} \text { overall }\end{array}$ & $\begin{array}{l}0.19 \\
0.68\end{array}$ & $\begin{array}{l}0.19 \\
0.40\end{array}$ & $\begin{array}{l}0.19 \\
0.41\end{array}$ & $\begin{array}{l}0.19 \\
0.41\end{array}$ & $\begin{array}{l}0.20 \\
0.41\end{array}$ \\
\hline
\end{tabular}

Dependent variable: Feature-adjusted, pre-tax real exchange rates, $r^{i, c}$. Estimation equation 15 . All models, excluding Seat, 21528 observations in 4044 groups. Constant, fixed effects, and country, brent, and time dummies are not reported. Standard errors in parentheses. Asterisks indicate the level of significance, $(*)$ at the $10 \%,(* *)$ at the $5 \%$, and $(* * *)$ at the $1 \%$ level. 


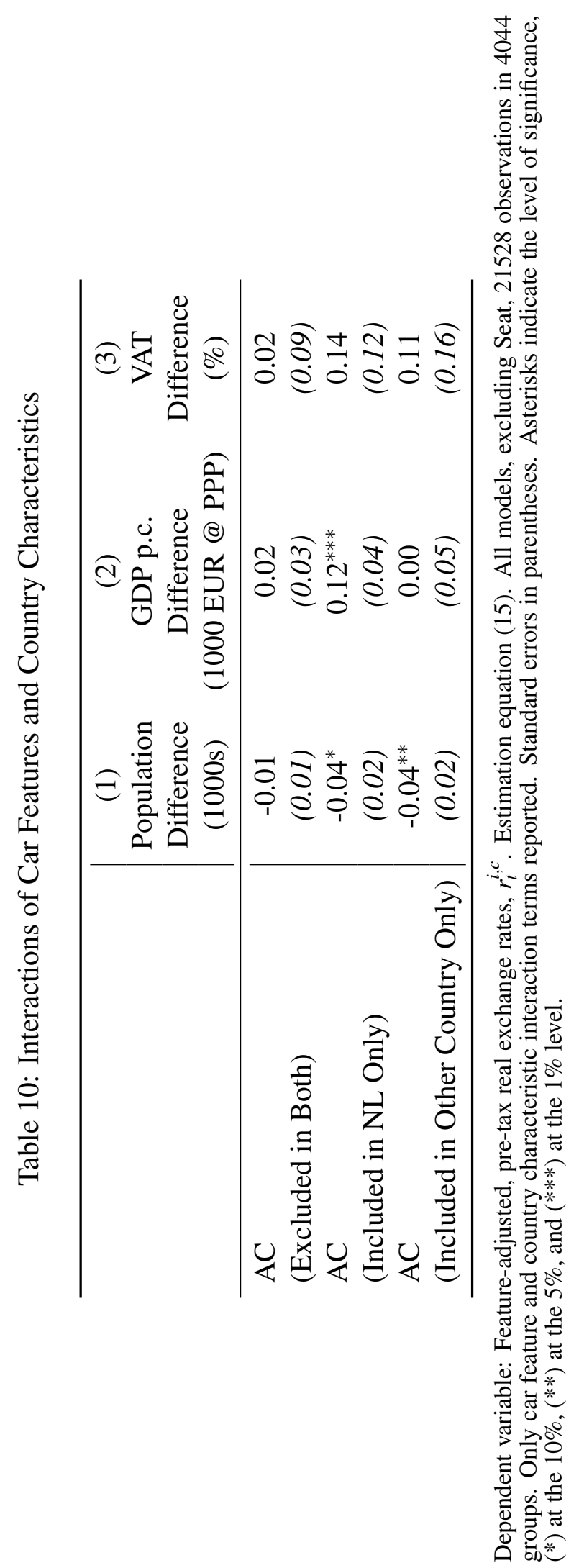


Table 11: Effect of Unbundling AC on the Real Exchange Rate by Country

\begin{tabular}{|c|c|c|}
\hline Country & $\begin{array}{c}\text { AC excluded } \\
\text { in both countries }\end{array}$ & $\begin{array}{l}\text { AC included in NL, } \\
\text { excluded in OC }\end{array}$ \\
\hline Austria & $\begin{array}{c}0.77 \\
(1.26)\end{array}$ & $\begin{array}{l}9.94^{* * *} \\
(2.09)\end{array}$ \\
\hline Belgium & $\begin{array}{l}-1.76 \\
(1.11)\end{array}$ & $\begin{array}{c}11.42^{* * *} \\
(1.49)\end{array}$ \\
\hline Bulgaria & $\begin{array}{l}-1.39 \\
(1.98)\end{array}$ & $\begin{array}{c}6.89 \\
(4.44)\end{array}$ \\
\hline Cyprus & $\begin{array}{l}-5.83^{* *} \\
(2.52)\end{array}$ & \\
\hline Czech Rep. & $\begin{array}{l}1.55 \\
(1.70)\end{array}$ & $\begin{array}{l}5.73^{* *} \\
(2.37)\end{array}$ \\
\hline Denmark & $\begin{array}{c}2.61 \\
(1.58)\end{array}$ & $\begin{array}{l}8.21^{* * *} \\
(1.26)\end{array}$ \\
\hline Estonia & $\begin{array}{l}2.50^{* *} \\
(1.26)\end{array}$ & $\begin{array}{c}10.33^{* * *} \\
(2.21)\end{array}$ \\
\hline Finland & $\begin{array}{l}-1.69 \\
(1.55)\end{array}$ & $\begin{array}{l}3.88^{*} \\
(2.32)\end{array}$ \\
\hline France & $\begin{array}{l}-1.67 \\
(1.05)\end{array}$ & $\begin{array}{c}5.24 \\
(5.39)\end{array}$ \\
\hline Germany & $\begin{array}{l}0.79 \\
(1.11)\end{array}$ & $\begin{array}{c}10.02^{* * *} \\
(1.32)\end{array}$ \\
\hline Greece & $\begin{array}{l}-4.54^{* *} \\
(1.92)\end{array}$ & $\begin{array}{l}-1.89 \\
(2.64)\end{array}$ \\
\hline Hungary & $\begin{array}{l}-2.45 \\
(1.48)\end{array}$ & $\begin{array}{l}4.98^{* * *} \\
(1.92)\end{array}$ \\
\hline Ireland & $\begin{array}{l}2.26 \\
(1.37)\end{array}$ & $\begin{array}{c}10.44^{* * *} \\
(1.63)\end{array}$ \\
\hline Italy & $\begin{array}{c}-3.83^{* * *} \\
(0.74)\end{array}$ & $\begin{array}{l}2.87^{* *} \\
(1.23)\end{array}$ \\
\hline Latvia & $\begin{array}{c}1.72 \\
(1.91)\end{array}$ & $\begin{array}{c}10.83^{* * *} \\
(2.42)\end{array}$ \\
\hline Lithuania & $\begin{array}{c}0.87 \\
(1.18)\end{array}$ & $\begin{array}{l}9.55^{* * *} \\
(2.55)\end{array}$ \\
\hline Luxembourg & $\begin{array}{c}0.14 \\
(0.98)\end{array}$ & $\begin{array}{c}11.76^{* * *} \\
(1.31)\end{array}$ \\
\hline Malta & $\begin{array}{l}-2.23^{*} \\
(1.30)\end{array}$ & $\begin{array}{c}32.14^{* * *} \\
(0.56)\end{array}$ \\
\hline Poland & $\begin{array}{c}0.57 \\
(1.53)\end{array}$ & $\begin{array}{l}8.18^{* * *} \\
(2.26)\end{array}$ \\
\hline Portugal & $\begin{array}{l}-1.01 \\
(1.13)\end{array}$ & $\begin{array}{l}5.74^{* * *} \\
(1.79)\end{array}$ \\
\hline Romania & $\begin{array}{l}2.97 \\
(2.59)\end{array}$ & $\begin{array}{c}7.41 \\
(4.61)\end{array}$ \\
\hline Slovakia & $\begin{array}{l}-2.56 \\
(1.62)\end{array}$ & $\begin{array}{l}3.16^{* *} \\
(1.42)\end{array}$ \\
\hline Slovenia & $\begin{array}{l}-1.21 \\
(1.45)\end{array}$ & $\begin{array}{l}5.14^{* *} \\
(2.43)\end{array}$ \\
\hline Spain & $\begin{array}{l}-0.88 \\
(1.24)\end{array}$ & $\begin{array}{l}8.72^{* * *} \\
(1.85)\end{array}$ \\
\hline Sweden & $\begin{array}{l}2.15 \\
(1.53)\end{array}$ & $\begin{array}{c}13.16^{* * *} \\
(1.76)\end{array}$ \\
\hline United Kgd. & $\begin{array}{c}2.85 \\
(1.95)\end{array}$ & $\begin{array}{c}4.31 \\
(2.90)\end{array}$ \\
\hline
\end{tabular}

All coefficients are country interactions relative to the default of AC being included as standard in both countries of interest. See notes to Table 9 


\section{A Data Appendix}

\section{A.1 Data Cleaning}

In this appendix we describe our procedure to standardize and clean the EC price data in more detail. The cleaning proceeds in the following sequence:

1. We convert all prices, for car models and for the various options, to the US numerical convention, i.e. commas denote the thousands separator, and periods denote the decimal separator. This is crucial since prices were reported using both the European and the US conventions, a fact which creates numerous order-of-magnitude errors which have to be manually corrected.

2. We convert all prices to euros. Some manufacturers report all prices in euros, but others report option prices in domestic currency for some models and in some periods. We use the exchange rate at the date of the report for currency conversion purposes.

3. We create dummy variables for the various options. A value of one signifies that the appropriate option is reported as standard for the model in a particular country. A value of zero signifies that the option is either unavailable for that model-country combination, or that a price is given for that option. A missing value signifies that we cannot determine whether the option was offered or not.

4. Some options require more detailed treatment: warranty information is reported in years and/or in kilometers, as is information on the availability of roadside assistance. We create the appropriate variables to facilitate correct comparison across borders.

5. There were several instances where we choose to disregard a data point. This occurs where the data, as reported, is clearly wrong. Examples include: an unreasonably high or low price, a pre-tax price which is higher than the after-tax price, or instances where the prices reported were clearly copied from adjacent columns by mistake. There are other instances where we choose to insert a data point. A typical case for this is where a pre-tax price is not reported, but the after-tax price is. Exploiting the data's cross section features (other models of the same manufacturer in the same period) as well as its time series features (same model in other periods), we are often able to insert the missing data with confidence. 


\section{A.2 Construction of Brand Perception Data}

The basis of the brand centrality and proximity measures are the Google search statistics available at Google Insights (http://www.google.com/insights/search/ \#). We are using the information of search terms that were entered simultaneously with any given car brand in our sample.

We extracted the statistics on "Web Search" in "all categories" for the time period "2004present" from the list of "Top searches" available after logging into a Google account. The search terms, submitted in UTF-8 encoding were: '“alfa romeo"', 'audi', 'bmw', 'citroen + CITROËN', 'daihatsu', 'fiat', 'ford', 'honda', 'hyundai', 'kia', 'lancia', "'land rover", 'mazda', 'mercedes + benz + daimler + "Mercedes-Benz", 'rover + "land rover"', 'mini + cooper', 'mitsubishi', 'nissan', 'opel + vauxhall', 'peugeot', 'renault', 'saab', 'seat', 'skoda + ŠKODA', 'subaru', 'suzuki', 'toyota', 'volkswagen + vw', 'volvo'. The data set was downloaded, separately for each country in our sample, in multiple sessions between August $13^{\text {th }}$, 2011 and August 19 $9^{\text {th }}$, 2011. Search results in Greek and Russian characters where transformed into ANSI coding and then translated. Terms in Bulgarian and Hungarian were examined by native speakers.

According to Google, the reported data are not exact, but approximations. The data was scaled and truncated from below at an unpublished number of searches, leading to shorter brand lists in smaller countries.

From this initial list of co-search terms we extract the ones that refer to other brands in our sample. In the case of double appearances of a given brand we use the maximum. In the case of "Toyota" in Ireland, for example, "Ford" shows up once as "Ford (15)" and once as "Ford Ireland (5)". We therefore use "15" as the joint search intensity of Ford and Toyota. Maintaining the example of "Toyota" in Ireland, a search in all years returns the cobrands: Ford 15+5, Nissan 15+5, Honda 10, Volkswagen 5, BMW 5, Mitsubishi 5, and Hyundai 5.

We summarize this information in a brand proximity matrix $\Psi_{c}$ for each country, with the value " 100 " on the diagonal, and zeros for brand pairs with no information on Google Insights. We convert this matrix into the symmetric matrix $S_{c}=v_{c} \Psi_{c}^{\prime} \Psi_{c} v_{c}$, where $v_{c}$ is the inverse of the Cholesky decomposition of the matrix obtained by setting all off-diagonal elements of $\Psi_{c}^{\prime} \Psi_{c}$ to zero.

Our measure of brand centrality for a given brand in a given country $c$ is the corresponding element of the Eigenvector of the largest Eigenvalue of matrix $S_{c}$. Using the largest Eigenvalue also guarantees that all elements of the Eigenvector are positive. 


\section{B Recent Developments in Regulation of the EU Car Mar- ket}

This appendix gives a short background regarding the regulatory environment relevant to our data. Since the late 1990s, the regulatory framework of the European new car market has radically changed. The most relevant regulations for the new car market during our sample period are

- 2002: EU Consumer Goods Directive (European Commission, 1999): EU-wide twoyear warranty, incl. used cars (Commission Directive 1999/44/EC),

- 2002: Block Exemption Regulation (European Commission, 2002): Delayed unbundling of sales, service, and warranty (Commission Regulation 1400/2002),

- 2005: Car Registration Directive (European Commission, 2004): Introduction of a Europe-wide car registration documents (Commission Directive 2003/127/EC amending 1999/37/EC)

The European Commission's (EC) interest in the evolution of price dispersion in the car market stems from the need to design block exemption regulations for the car market. These block exemption regulations exempt certain agreements between manufacturers and downstream dealers and repair shops from the EU ban on restrictive business practices, in particular from Article 101(1) of the Treaty on the Functioning of the European Union. This is in contrast to other consumer goods markets, where any "prevention, restriction or distortion of competition within the internal market" is prohibited (Article 101(1) of the Treaty). Replacing the principles of Article 101(1) without giving up competition in the new car market completely requires a large set of rules tailored to the car market, which are collected in the block exemption regulation. The block exemption regulation grants the car industry special rights, for example to determine how and by whom their new cars can be sold, as long as certain conditions are met.

Conditions, which the 2002 block exemption regulation (European Commission, 2002) specifies, are among others:

- Manufacturers must choose between selective and exclusive distribution; i.e. either the manufacturer assigns regions to sellers, but permits resale by third-party dealers, or he selects dealers without assigning regions, but prohibits all sales to third-party dealers. 
- Manufacturers cannot prohibit the dealer to sell cars of other brands in the same location.

- Manufacturers cannot force dealers to operate a repair shop; independent repair shops get better access to OEM spare parts, tools, and technical information; spare parts can be obtained directly from its manufacturer, not necessarily the car maker

- Manufacturers cannot impose "restrictions impeding dealers in one Member State to sell vehicles with specifications pertaining to another Member State (e.g. right-hand drive cars)" (European Commission DG-COMP, 2002, p.13).

Despite these conditions, manufacturers have many levers to restrict new car trade across intra-European borders. For example, they can prohibit sales from authorized dealers to resellers. Due to these restrictions, there are only few dealers selling cars Europe-wide. The European car reimport market is dominated by car brokers, who have to obtain documentation from their customers to prove the "end-consumer status" to the manufacturer or brand dealership.

The eagerness of the EC to further liberalize the European new passenger car market seems to have been limited. In its 2009 report it states: "The Commission's third objective was to encourage intra-brand competition across borders. The objective appears to have been achieved, as prices between Member States have converged and cases of hindrances to parallel trade, including complaints from final consumers, have significantly diminished." (European Commission, 2009, p.6)

A new block exemption regulation (European Commission, 2010) went into effect on June $1^{\text {st }} 2010$ for the markets for repair, maintenance and spare parts. The new regulations on the purchase, sale or resale of new motor vehicles replaced European Commission (2002) starting June $1^{\text {st }} 2013$, and are thus not relevant for our sample period. Nevertheless, the changes of the new block exemption regulation showcase where - in the EC's point of view - competition was most severely constrained during the sample period. In particular, the new regulation:

- prohibits discrimination by manufacturers of independent repair shops in obtaining technical information and spare parts, if the manufacturer's repair shop network has above $30 \%$ market share.

- prohibits conditioning manufacturer warranty on the car being serviced (oil changes, etc.) at manufacturer-authorized garages only. However, repairs covered by the warranty can still be restricted to the manufacturer-authorized network. 
- lifts some restrictions on manufacturers imposed by European Commission (2002): Under certain conditions, manufacturers are again allowed to require single-brand showrooms. This is supposed to reduce distribution costs which are claimed to have increased due to European Commission (2002) because manufactures increased the investments required from the dealers to ensure a unique and separate brand presentation.

Clearly, even under the new regulation car manufacturers will have opportunities to limit cross-country new car trade.

\section{Additional Regression Results, Country Comparisons, Robustness Checks}

\section{C.1 Average Price Deviation by Country}

Table 12 shows that the Netherlands, Spain and Italy have the most representative car prices in Europe. Prices in Denmark and the UK tend to be in the extremes. Interestingly, despite its central location, infrastructure, and size, the new car prices for any given model in Germany are far from the European average. Feature-adjusted prices are more dispersed than unadjusted prices.

[Table 12 about here.]

\section{C.2 Tax Effect by Segment}

[Table 13 about here.]

All regression specifications of Table 3 show a positive response of prices to an increase in VAT and fuel taxes. In this appendix we explore if this could be the result of conspicuous consumption, i.e. that fuel-inefficient cars are a Veblen good. A well-known example, although not in our data set, is the Hummer brand - high fuel consumption as a status symbol, a way for consumers to differentiate themselves from the crowd. Table 13 shows some evidence for this hypothesis. It shows the coefficient of the interaction terms between taxes (VAT, petrol tax, and the diesel-petrol tax differential) and car segments in a regression specification that is otherwise identical to column 2 of Table 3 . The positive relationship between VAT and petrol tax rates and prices increases with the car segment. The effect for the highest 
segments executive (E) and luxury $(\mathrm{F})$ is double to four times as large as the effect among small (B) cars.

\section{C.3 Country-Specific Time Trends}

\section{[Figure 7 about here.]}

New car prices in Europe during the past decade followed a marked price pattern. Increasing until 2007, prices have fallen since. Some countries did not follow this common trend. Most notably, as Figure 7 shows, Germany and Spain display fairly stable conditional price levels since 2007.

\section{References}

European Commission, 1999. Directive 1999/44/EC of the European Parliament and of the Council of 25 May 1999 on certain aspects of the sale of consumer goods and associated guarantees. Official Journal of the European Communities 1999 (L 171), 12-16.

European Commission, 2002. Commission Regulation 1400/2002 of 31 July 2002 on the application of Article 81(3) of the Treaty to categories of vertical agreements and concerted practices in the motor vehicle sector. Official Journal of the European Communities 2002 (L 203), 30-41.

European Commission, 2004. Commission Directive 2003/127/EC of 23 December 2003 amending Council Directive 1999/37/EC on the registration documents for vehicles. Official Journal of the European Communities 2004 (L 10), 29-53.

European Commission, May 2009. Commission evaluation report on the operation of Regulation (EC) 1400/2002 concerning motor vehicle distribution and servicing. Evaluation report, Commission of the European Communities.

European Commission, 2010. Commission Regulation 461/2010 of 27 May 2010 on the application of Article 101(3) of the Treaty on the functioning of the European Union to categories of vertical agreements and concerted practices in the motor vehicle sector. Official Journal of the European Communities 2010 (L 129), $52-57$.

European Commission DG-COMP, July 2002. Distribution and servicing of motor vehicles in the European Union: Explanatory brochure for Commission Regulation (EC) no 1400/2002 of 31 July 2002. Explanatory brochure, Commission of the European Communities - Directorate General for Competition. 
Figure 7: Time Trends

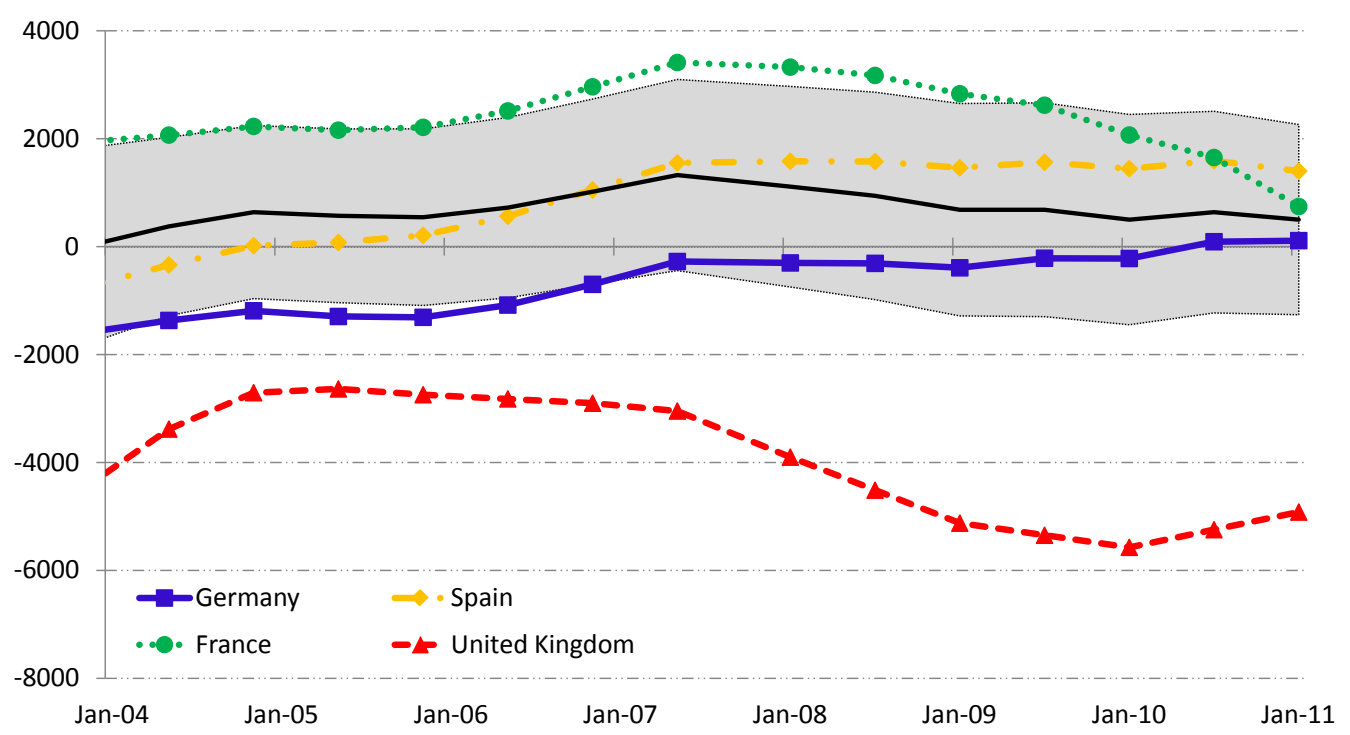

The graph shows the country-specific time trends in prices from column 3 in Table 3 The average across 25 countries (excluding the short time series of Bulgaria and Romania) is given by the light solid line, and the one standard deviation interval across countries by the shaded region. All models, excluding Seat. The prices are in EUR, feature-adjusted, and pre-tax. 
Table 12: Absolute Price Deviations from EU Average, by Country

\begin{tabular}{|c|c|c|c|c|}
\hline \multirow[b]{2}{*}{ country } & \multicolumn{2}{|c|}{$\begin{array}{l}\text { feature } \\
\text { adjusted }\end{array}$} & \multicolumn{2}{|c|}{$\begin{array}{c}\text { not feature } \\
\text { adjusted }\end{array}$} \\
\hline & mean & sd. & mean & sd. \\
\hline Netherlands & 681 & 650 & 650 & 639 \\
\hline Spain & 694 & 609 & 654 & 595 \\
\hline Italy & 705 & 647 & 666 & 654 \\
\hline Luxembourg & 795 & 623 & 756 & 616 \\
\hline Belgium & 810 & 650 & 776 & 634 \\
\hline France & 825 & 777 & 823 & 773 \\
\hline Portugal & 839 & 829 & 789 & 827 \\
\hline Ireland & 856 & 900 & 805 & 887 \\
\hline Austria & 877 & 708 & 869 & 699 \\
\hline Greece & 914 & 982 & 801 & 976 \\
\hline Estonia & 951 & 697 & 940 & 687 \\
\hline Lithuania & 967 & 873 & 957 & 862 \\
\hline Slovenia & 972 & 832 & 941 & 832 \\
\hline Latvia & 994 & 825 & 948 & 820 \\
\hline Bulgaria & 1080 & 884 & 1044 & 889 \\
\hline Finland & 1095 & 957 & 1022 & 955 \\
\hline Slovakia & 1108 & 1053 & 1091 & 1041 \\
\hline Cyprus & 1227 & 1311 & 1156 & 1264 \\
\hline Germany & 1233 & 784 & 1195 & 766 \\
\hline Hungary & 1237 & 997 & 1249 & 981 \\
\hline Romania & 1276 & 1260 & 1261 & 1268 \\
\hline Poland & 1419 & 1404 & 1412 & 1387 \\
\hline Czech Rep. & 1496 & 1261 & 1434 & 1247 \\
\hline Sweden & 1533 & 1563 & 1514 & 1546 \\
\hline Malta & 1549 & 1297 & 1507 & 1289 \\
\hline UK & 1912 & 2484 & 1874 & 2434 \\
\hline Denmark & 1915 & 1632 & 1896 & 1606 \\
\hline
\end{tabular}

Mean and standard deviation of the absolute deviation of the pre-tax car price in a given country from the EU average, calculated for each model and survey, in euros. The countries are sorted by the mean absolute deviation of the feature adjusted price. Seat models and models available in only one country are excluded. 
Table 13: Taxes by Segment

\begin{tabular}{|c|c|c|c|c|c|}
\hline Segment & $\begin{array}{l}\text { Segment } \\
\text { Constant }\end{array}$ & $\begin{array}{l}\text { VAT } \\
(\%)\end{array}$ & $\begin{array}{l}\text { Petrol Tax } \\
\quad(\mathrm{ct} / \mathrm{l})\end{array}$ & $\begin{array}{l}\text { Diesel-Petr } \\
\text { (petrol cars) }\end{array}$ & $\begin{array}{l}\text { l Tax (ct/l) } \\
\text { (diesel cars) }\end{array}$ \\
\hline $\operatorname{Mini}(\mathrm{A})$ & $\begin{array}{c}-3075.38^{* *} \\
(1477.77)\end{array}$ & $\begin{array}{c}114.62^{* * *} \\
(24.61)\end{array}$ & $\begin{array}{c}77.77^{* * *} \\
(10.58)\end{array}$ & $\begin{array}{c}71.62^{* * *} \\
(13.51)\end{array}$ & $\begin{array}{c}118.82^{* * *} \\
(24.46)\end{array}$ \\
\hline Small (B) & $\begin{array}{c}-250.35 \\
(1479.96)\end{array}$ & $\begin{array}{l}45.44^{*} \\
(23.45)\end{array}$ & $\begin{array}{c}70.30^{* * *} \\
(10.60)\end{array}$ & $\begin{array}{c}62.69^{* * *} \\
(13.68)\end{array}$ & $\begin{array}{l}28.65^{*} \\
(16.26)\end{array}$ \\
\hline Medium (C) & $\begin{array}{c}-6.38 \\
(1494.51)\end{array}$ & $\begin{array}{l}54.96^{* *} \\
(23.22)\end{array}$ & $\begin{array}{c}89.90^{* * *} \\
(10.09)\end{array}$ & $\begin{array}{c}77.84^{* * *} \\
(13.08)\end{array}$ & $\begin{array}{c}52.06^{* * *} \\
(15.18)\end{array}$ \\
\hline Large (D) & $\begin{array}{c}-777.44 \\
(1526.13)\end{array}$ & $\begin{array}{c}132.47^{* * *} \\
(28.64)\end{array}$ & $\begin{array}{c}116.88^{* * *} \\
(10.69)\end{array}$ & $\begin{array}{c}105.82^{* * *} \\
(14.08)\end{array}$ & $\begin{array}{c}91.67^{* * *} \\
(14.19)\end{array}$ \\
\hline Executive (E) & $\begin{array}{c}826.44 \\
(1790.34)\end{array}$ & $\begin{array}{c}237.54^{* * *} \\
(46.04)\end{array}$ & $\begin{array}{c}121.26^{* * *} \\
(14.97)\end{array}$ & $\begin{array}{c}134.46^{* * *} \\
(21.88)\end{array}$ & $\begin{array}{l}51.63^{* *} \\
(25.28)\end{array}$ \\
\hline Luxury $(\mathrm{F})$ & $\begin{array}{l}5959.12^{* *} \\
(2794.23)\end{array}$ & $\begin{array}{c}342.87^{* * *} \\
(123.42)\end{array}$ & $\begin{array}{c}200.20^{* * *} \\
(39.47)\end{array}$ & $\begin{array}{c}54.03 \\
(61.67)\end{array}$ & $\begin{array}{c}232.78^{* * *} \\
(68.20)\end{array}$ \\
\hline Multipurpose (G) & (base) & $\begin{array}{c}238.21^{* * *} \\
(68.94)\end{array}$ & $\begin{array}{c}132.75^{* * *} \\
(19.02)\end{array}$ & $\begin{array}{c}156.60^{* * *} \\
(29.46)\end{array}$ & $\begin{array}{c}88.27^{* * *} \\
(26.59)\end{array}$ \\
\hline
\end{tabular}

Dependent variable: Feature-adjusted, pre-tax euro prices, $P_{t}^{i, c}$. All models, excluding Seat. Regression specification (2) of Table 3 augmented by taxes interacted with segment. Bootstrap standard errors in parentheses. Asterisks indicate the level of significance, $(*)$ at the $10 \%,(* *)$ at the $5 \%$, and $(* * *)$ at the $1 \%$ level. 